\title{
Removal of Uranyl Ion from Wastewater by Magnetic Adsorption Material of Polyaniline Combined with $\mathrm{CuFe}_{2} \mathrm{O}_{4}$
}

\author{
Xinrui Feng, ${ }^{1}$ Shaoshuai Sun, ${ }^{1}$ Ge Cheng, ${ }^{1}$ Lei Shi $\mathbb{D},{ }^{1}$ Xiangshan Yang $\mathbb{D}^{1},{ }^{1}$ and Yibo Zhang ${ }^{2}$ \\ ${ }^{1}$ NHC Key Laboratory of Radiobiology, College of Public Health, Jilin University, Changchun 130021, China \\ ${ }^{2}$ Changchun Institute of Applied Chemistry, Chinese Academy of Sciences, Changchun 130022, China
}

Correspondence should be addressed to Lei Shi; shilei@jlu.edu.cn and Xiangshan Yang; yangxs@jlu.edu.cn

Received 12 January 2021; Revised 18 March 2021; Accepted 3 April 2021; Published 22 April 2021

Academic Editor: S Rangabhashiyam

Copyright (C) 2021 Xinrui Feng et al. This is an open access article distributed under the Creative Commons Attribution License, which permits unrestricted use, distribution, and reproduction in any medium, provided the original work is properly cited.

\begin{abstract}
The magnetic adsorption material of polyaniline (PANI) with amino functional group combined with $\mathrm{CuFe}_{2} \mathrm{O}_{4}\left(\mathrm{CuFe} \mathrm{O}_{4} / \mathrm{PANI}\right.$ nanocomposite) has been described in this work. It has been characterized by TEM, XRD, XPS, BET, FTIR, and VSM, respectively. Significantly, it exhibits extremely high maximum adsorption capacity $(322.6 \mathrm{mg} / \mathrm{g})$ for removal of uranyl ions from wastewater at a $\mathrm{pH}$ of 4 . The adsorption process is consistent with the quasisecond-order kinetic equation, and the isotherm and kinetic data are accurately described by the Langmuir isothermal adsorption model. Furthermore, the magnetic $\mathrm{CuFe}_{2} \mathrm{O}_{4} / \mathrm{PANI}$ displays stable adsorption performance for uranyl ions after five cycles of recovery in acid medium, which indicates it possesses good recovery due to its magnetism and excellent regeneration ability for reusability.
\end{abstract}

\section{Introduction}

In recent years, nuclear power is widely considered as a sustainable solution to the global demand for energy [1]. With the rapid expansion of the atomic energy industry as well as nuclear science and technology, the development of new green energy such as nuclear energy not only brings huge social and economic benefits to human society but also arise increasingly serious environmental problems. Nuclear energy as one of the clean energy sources, its series of environmental and safety problems brought about by its sustainable development have been paid close attention to nowadays. Meanwhile, due to the increasing discharge of radioactive nuclides in wastewater and the increasingly complex composition, people are paying more and more attention to the harmful problem it arises for human health and the ecological environment as well. Environmental contaminant releases that contain uranium are among the more serious problems that must be confronted by the decontamination programs. Uranium with natural radioactivity is one of the most basic nuclides in the field of nuclear research and the core resource of nuclear energy development. [2]. As one of the most common pollutants, uranium also has the characteristics of strong radioactivity, high carcinogenicity, and toxicity, which will cause great radiation harm to the human organism and the ecological environment. Under oxidizing conditions, dissolved uranium is predominantly in the U (VI) (uranyl ions) form and is potentially quite mobile in the aquatic environment. Therefore, removal of uranyl ions from aqueous solution is becoming of great importance for not only sustainable development of nuclear energy but also the environment protection.

More and more research is focused on the removal and recycling of uranium in wastewater $([3,4]$; Ozdemir and Usanmaz, [5]). At present, the commonly used treatment methods for industrial wastewater containing uranium and heavy metal ions mainly include chemical precipitation method [6], extraction method [7], biological method [8], membrane filtration method [9], and adsorption method [10-12]. Adsorption method, as a type of environmental protection, belongs to a low harmful treatment to remove wastewater of radionuclides and heavy metal ion (lead, mercury, cadmium, chromium, etc.), due to its economic advantage, species diversity, good stability, high applicability, 
simple operation, high treatment efficiency, and better regeneration [13-17].

Screening suitable adsorption materials with high adsorption capacity is becoming extremely important to remove uranium efficiently from wastewater. [18-20]. The commonly used adsorption materials are including graphene, carbon nanotubes, some carbon materials, cellulose, polymer materials, kaolin, clay, mineral, organic-inorganic hybrid adsorption materials, ion-imprinted polymers, and other composite materials, but their limitations are focused on not very high adsorption efficiency, high cost, low selectivity, long preparation period, and difficulty of recycling. [2123] [24]. Therefore, the development and utilization of new high efficiency of uranium adsorption material are one of the most important issues of concern to be solved at present.

Magnetic composite nanomaterials have been widely used in environmental protection, catalysis, and biomedicines and have broad application prospects. [25-28]. A large number of studies have been carried out on the removal of heavy metals in wastewater by using magnetic nanoparticles as magnetic core in the composite adsorption materials. It has also been proved that it has the characteristics of strong magnetism, good adsorption, easy separation, and collection under the action of an external magnetic field [29-33]. More importantly, the functional groups of magnetic nanocomposite which is proper prepared based on different matrix can be designed according to the adsorption selectivity of the adsorption material for specific radionuclides. The advantages of it combined with other materials can complete and improve the comprehensive performance, which would not be obtained by a single component. Many new combination properties can solve the problem much better than the single magnetic nanomaterial showing low adsorption performance for pollutants [34, 35].

Polyaniline (PANI) is a type of polymer compound with high conductivity, which contains a large number of amino and imine groups [36]. As the exists of the abundant amounts of primary and secondary amino groups, PANI is expected to have a strong affinity with heavy metal ions by redox reaction $[37,38]$. Due to its low production cost, simple synthesis method, good chemical, and environmental stability, PANI has been widely applied to the adsorption of heavy metal pollutants from wastewater in recent years [39-41]. It has also been found that the magnetic PANI nanocomposite modified with GO composites would attract materials with exceptional ability in the selective extraction of trace U (VI) from aqueous solutions [42, 43]. It highlights the extensive applicability of these novel materials in the selective extraction and separation of trace uranyl ions from aqueous solution in nuclear fuel extraction processes.

Therefore, magnetic adsorption material of polyaniline (PANI) combined with $\mathrm{CuFe}_{2} \mathrm{O}_{4}\left(\mathrm{CuFe}_{2} \mathrm{O}_{4} / \mathrm{PANI}\right.$ nanocomposite) has been synthesized in this work. In the meanwhile, the amino functional groups with complexation for uranyl ions were introduced, which would improve the adsorption capacity of the novel materials. The new type of magnetic $\mathrm{CuFe}_{2} \mathrm{O}_{4} / \mathrm{PANI}$ nanocomposite for trace uranyl ions adsorption capacity in aqueous solution under different operating conditions was studied in detail. It was characterized by
TEM, FTIR, XRD, XPS, and BET, respectively, and batch adsorption experiments were carried out as well to study the effects on the uranium adsorption of various experimental parameters, such as $\mathrm{pH}$ value, contact time, temperature, and initial concentration. The adsorption kinetics, isotherm models, and thermodynamics were evaluated in detail to understand the adsorption process. Finally, the recycling regeneration of the adsorption nanocomposite for its reusability was analysed in detail through the experiments of adsorption/desorption cycle regeneration.

\section{Experimental}

2.1. Materials and Reagents. The chemical reagents used in this study were all of analytical grade with $98-99 \%$ purity. It includes copper sulfate $\left(\mathrm{CuSO}_{4} \cdot 5 \mathrm{H}_{2} \mathrm{O}\right)$, ferric chloride $\left(\mathrm{FeCl}_{3} \cdot 6 \mathrm{H}_{2} \mathrm{O}\right)$, polyethylene glycol 6000 (PEG), potassium hydroxide $(\mathrm{KOH})$, hydrochloric acid $(\mathrm{HCl})$, aniline $\left(\mathrm{C}_{6} \mathrm{H}_{7} \mathrm{~N}\right)$, ethyl alcohol $\left(\mathrm{C}_{2} \mathrm{H}_{6} \mathrm{O}\right)$, and ammonium thiosulfate $\left(\left(\mathrm{NH}_{4}\right)_{2} \mathrm{~S}_{2} \mathrm{O}_{3}\right)$. All the analytical grade chemical reagents used in this study were without further purification. Freshly deionized water was used as the dispersion medium. The stock uranium (U (VI)) solution was prepared by dissolving the appropriate amounts of uranyl nitrate hexahydrate $\left[\mathrm{UO}_{2}\left(\mathrm{NO}_{3}\right)_{2} \cdot 6 \mathrm{H}_{2} \mathrm{O}\right]$ in deionized water. The concentration of uranium stock solution is $1000 \mathrm{mg} / \mathrm{L}$, which is diluted to $5 \sim 300 \mathrm{mg} / \mathrm{L}$ by gradient dilution method.

2.2. Instrumentations. Surface morphological images were characterized by transmission electron micrograph (TEM) (FEI Tecnai G2) at an accelerating voltage of $200 \mathrm{kV}$. The functional groups of the materials were confirmed by Fourier transform infrared (FT-IR) (Vertex70, Bruker company). The materials were pelletized using $\mathrm{KBr}$ prior to FTIR measurement. XRD analysis was carried out on a D8 Advance instrument (Bruker company) with $\mathrm{Cu} \mathrm{K} \alpha$ radiation source $(\lambda=1.5406 \AA)$. The operating condition was at a scan rate of $3^{\circ} / \mathrm{min}$ from $10^{\circ}$ to $90^{\circ}$ to obtain the XRD pattern. Surface areas of samples were determined from $\mathrm{N}_{2}$ adsorption isotherms at $77.3 \mathrm{~K}$ with the BET method using a Micromeritics ASAP 2010 analyzer prior to the surface area measurement, and the samples were outgassed at $120^{\circ} \mathrm{C}$ for $27 \mathrm{~h}$ under a reduced pressure of $6.58 \times 10^{-5}$ Torr. X-ray photoelectron spectroscopy (XPS) spectra were obtained on a VG Thermo Escalab 250Xi spectrometer operated at $120 \mathrm{~W}$. VSM analysis was carried out on the condition of hysteresis loop, which normal temperature and the maximum magnetic field applied were $2 \mathrm{~T}$. Temperature scanning rate was $1 \mathrm{~K} / \mathrm{min}$, vibration amplitude was $4 \mathrm{~cm}$, and scanning twice each time. The uranyl ion concentration was determined by a trace uranium analyzer (WGJ-III, Institute of comparative geology of nuclear industry).

\subsection{Synthesis of the Adsorption Materials}

2.3.1. Synthesis of $\mathrm{CuFe}{ }_{2} \mathrm{O}_{4}$ Nanoparticles. $\mathrm{CuFe}_{2} \mathrm{O}_{4}$ nanoparticles were prepared by thecoprecipitation technique. $4.05 \mathrm{~g}$ $\mathrm{FeCl}_{3} \cdot 6 \mathrm{H}_{2} \mathrm{O} \mathrm{FeCl}$ and $2.93 \mathrm{~g} \mathrm{CuSO}_{4} \cdot 5 \mathrm{H}_{2} \mathrm{O}$ were dissolved in $200 \mathrm{~mL} 1 \mathrm{wt} \%$ PEG solution. Stir the solution continuously for about 60 minutes to ensure a balance between all 

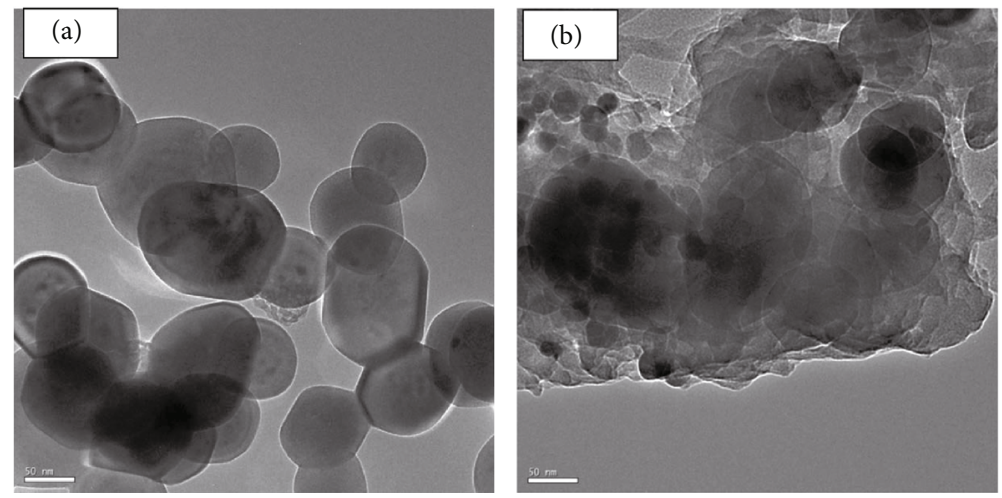

Figure 1: (a) TEM of $\mathrm{CuFe}_{2} \mathrm{O}_{4}$ nanoparticles and (b) TEM of $\mathrm{CuFe}_{2} \mathrm{O}_{4} / \mathrm{PANI}$ nanocomposite.

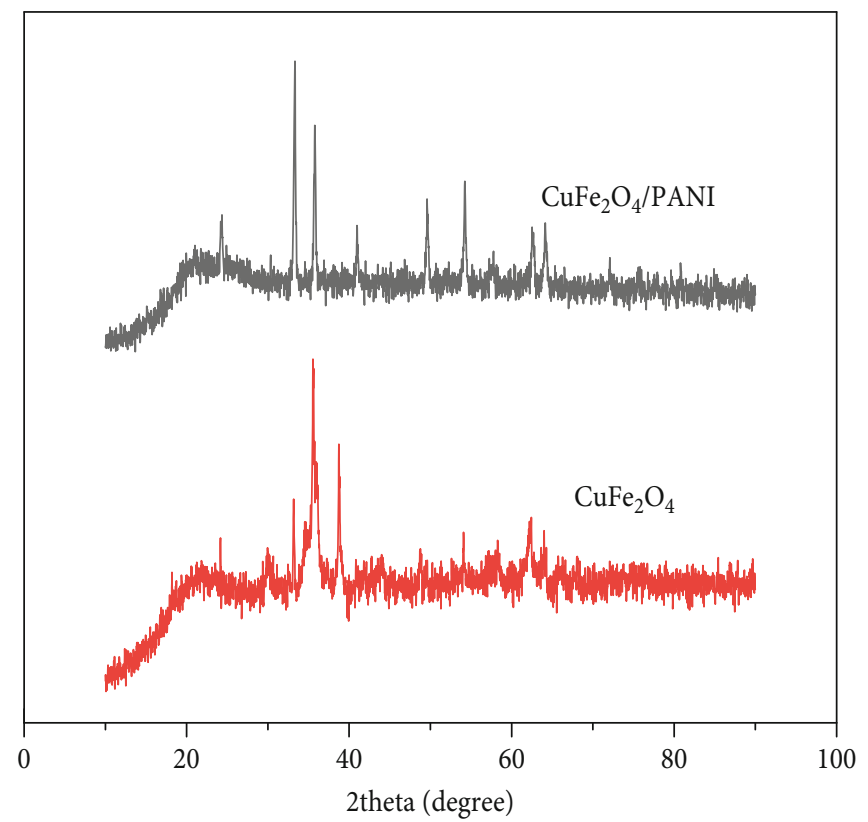

Figure 2: XRD of $\mathrm{CuFe}_{2} \mathrm{O}_{4}$ nanoparticles and $\mathrm{CuFe}_{2} \mathrm{O}_{4} / \mathrm{PANI}$ nanocomposite.

ingredients. The $\mathrm{pH}$ of the mixture was adjusted to 8 with adding $3 \mathrm{~mol} / \mathrm{L} \mathrm{KOH}$ solution. The mixture continued to be stirred magnetically for three hours and then aged overnight. The precipitate was filtered and washed repeatedly with distilled water until there were no $\mathrm{SO}_{4}{ }^{2-}$ and $\mathrm{Cl}^{-}$ions. Then, it was dried in a constant temperature drying oven at $50^{\circ} \mathrm{C}$ for $12 \mathrm{~h}$ and calcined at $600^{\circ} \mathrm{C}$ for $4 \mathrm{~h}$, and finally, $\mathrm{CuFe}_{2} \mathrm{O}_{4}$ nanoparticles were obtained in the end.

2.3.2. Synthesis of $\mathrm{CuFe}_{2} \mathrm{O}_{4} / P A N I$ Nanocomposite. $\mathrm{CuFe}_{2} \mathrm{O}_{4} /-$ PANI nanocomposite was prepared by chemical in situ polymerization. $2 \mathrm{~g} \mathrm{CuFe}_{2} \mathrm{O}_{4}$ nanoparticles were dispersed in $200 \mathrm{~mL} 2 \mathrm{~mol} / \mathrm{L}$ hydrochloric acid solution and stirred vigorously for 10 minutes. A certain amount of $1.2 \mathrm{~g}$ distilled aniline monomers was added to the above mixture and then stirred continuously for $60 \mathrm{~min}$. Then, $20 \mathrm{~mL} 20 \mathrm{mmol}$ $\left(\mathrm{NH}_{4}\right)_{2} \mathrm{~S}_{2} \mathrm{O}_{8}$ solution was added drop by drop to the mixture as a polymerization initiator. An immediate change in the color of the molecules was observed. The suspension was stirred to complete the polymerization process in about $12 \mathrm{~h}$.
Finally, the $\mathrm{CuFe}_{2} \mathrm{O}_{4} / \mathrm{PANI}$ nanocomposite was filtered, rinsed repeatedly with distilled water and anhydrous ethanol, and dried in a constant temperature drying oven at $70^{\circ} \mathrm{C}$ for $12 \mathrm{~h}$.

2.4. Batch Adsorption Experiments. A series of uranium solutions with different concentrations $(5 \sim 300 \mathrm{mg} / \mathrm{L})$ were prepared. For adsorption studies, $5 \mathrm{mg} \mathrm{CuFe}_{2} \mathrm{O}_{4}$ nanoparticles and $\mathrm{CuFe}_{2} \mathrm{O}_{4} / \mathrm{PANI}$ nanocomposite was mixed, respectively, with $9 \mathrm{~mL}$ uranium solution with a concentration of $100 \mathrm{mg} / \mathrm{L}$ in a $10 \mathrm{~mL}$ centrifuge tube. The $\mathrm{pH}$ value of uranium solution was adjusted to $2 \sim 6$ by with $1 \mathrm{mg} / \mathrm{L}$ hydrochloric acid and $0.1 \mathrm{mg} / \mathrm{L}$ sodium hydroxide, and the solution was adsorbed at $25^{\circ} \mathrm{C}, 35^{\circ} \mathrm{C}$, and $45^{\circ} \mathrm{C}$, respectively, for $5 \mathrm{~min}$ to $120 \mathrm{~min}$. The mixture was centrifuged to take out the supernatant after absolutely adsorption, without inhaling the solid particles for intermittent adsorption experiment. Adsorption capacity $\left(Q_{e}\right)$ is calculated according to Equation (1) 


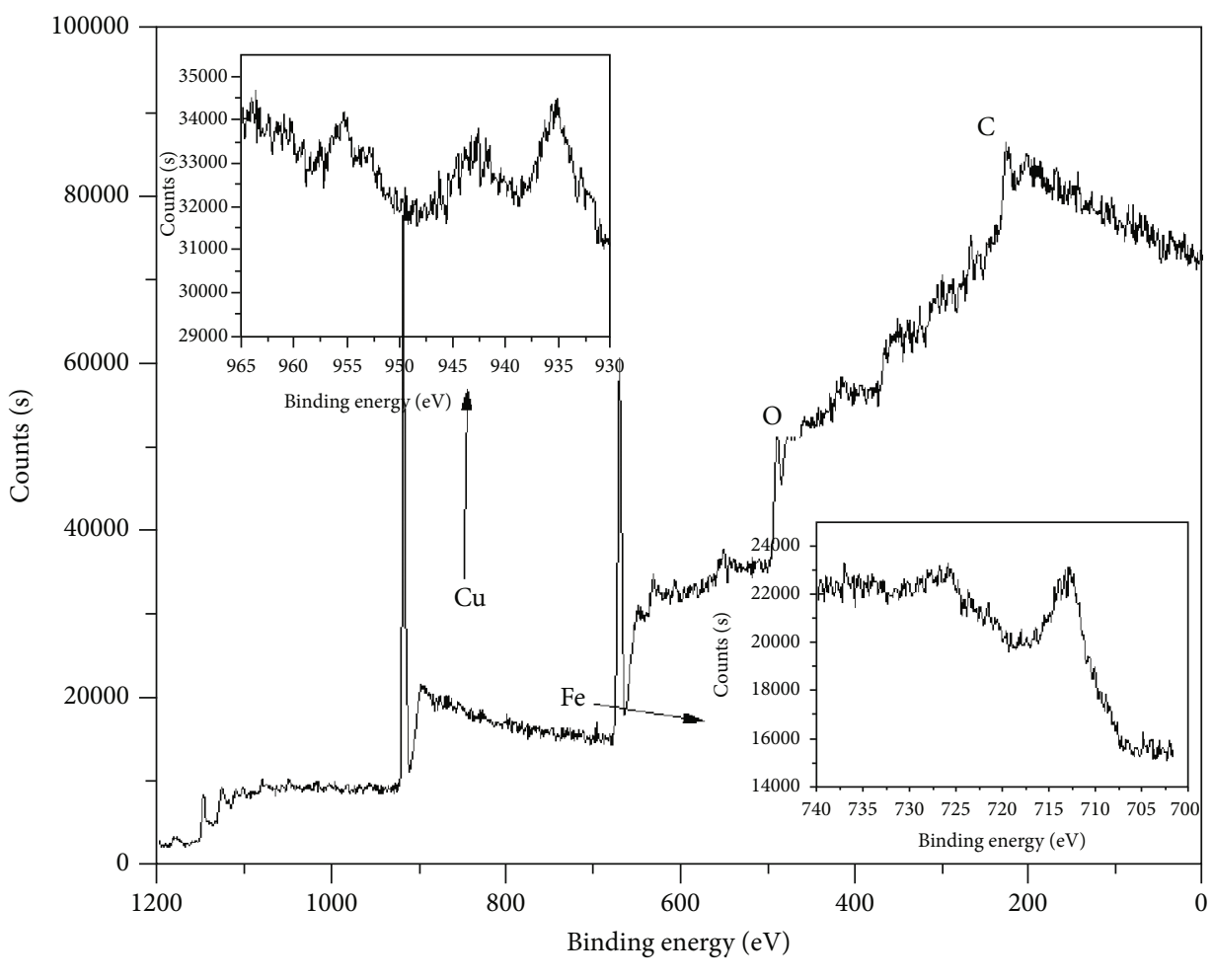

$-\mathrm{CuFe}_{2} \mathrm{O}_{4}$

(a)

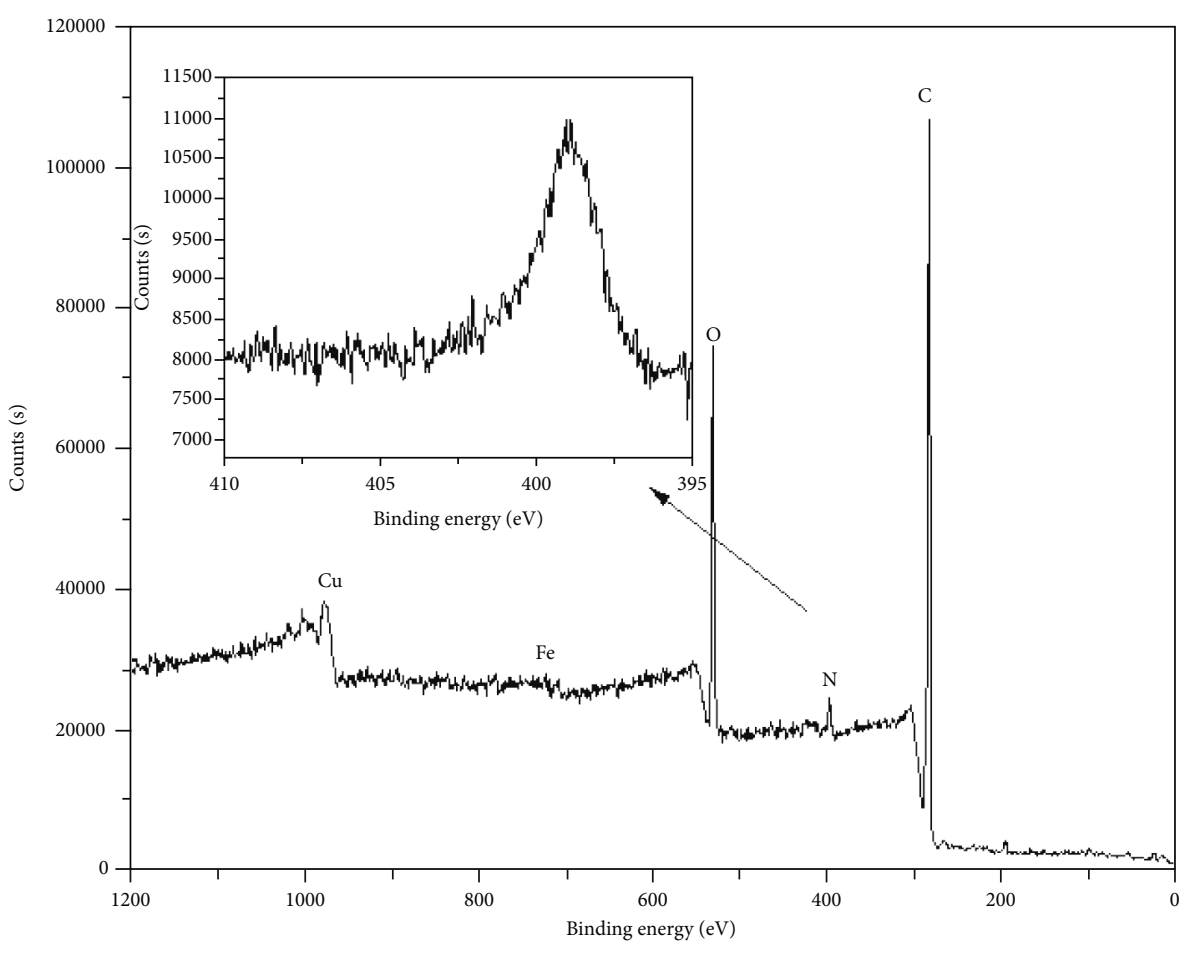

(b)

Figure 3: X-ray photoelectron spectroscopy of (a) $\mathrm{CuFe}_{2} \mathrm{O}_{4}$ nanoparticles and (b) $\mathrm{CuFe}_{2} \mathrm{O}_{4} / \mathrm{PANI}$ nanocomposite. 

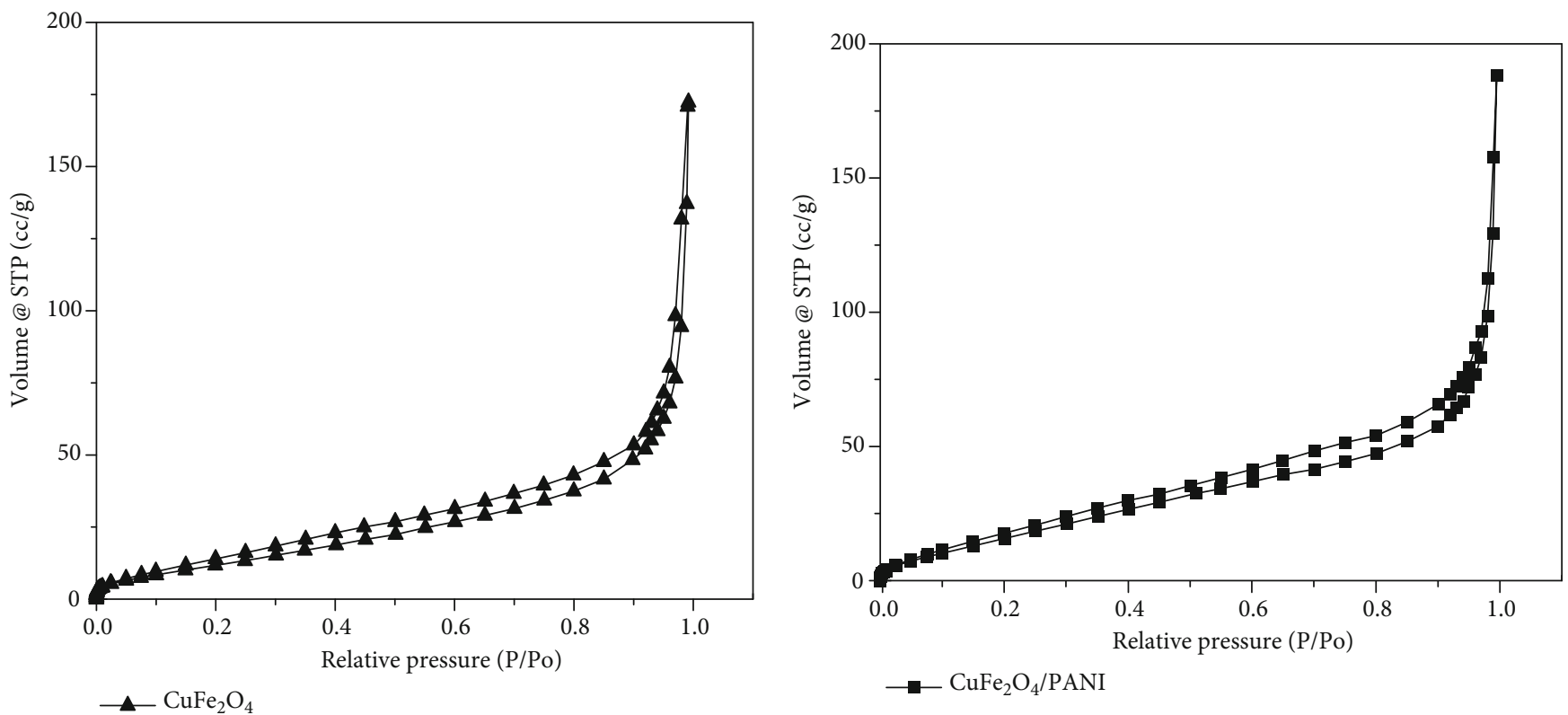

Figure 4: $\mathrm{N}_{2}$ adsorption-desorption curves of $\mathrm{CuFe}_{2} \mathrm{O}_{4}$ nanoparticles and $\mathrm{CuFe}_{2} \mathrm{O}_{4} / \mathrm{PANI}$ nanocomposite.

TABLE 1: Analysis of specific surface area and pore volume of $\mathrm{CuFe}_{2} \mathrm{O}_{4}$ nanoparticles and $\mathrm{CuFe}_{2} \mathrm{O}_{4} / \mathrm{PANI}$ nanocomposite.

\begin{tabular}{lccc}
\hline Sample & Surface area $\left(\mathrm{m}^{2} / \mathrm{g}\right)$ & Average pore volume $\left(\mathrm{cm}^{3} / \mathrm{g}\right)$ & Average pore diameter $(\mathrm{nm})$ \\
\hline $\mathrm{CuFe}_{2} \mathrm{O}_{4}$ & 91.1 & 0.258 & 3.06 \\
$\mathrm{CuFe}_{2} \mathrm{O}_{4} / \mathrm{PANI}$ & 153 & 0.280 & 3.83 \\
\hline
\end{tabular}

$$
Q_{e}=\left(C_{0}-\mathrm{Ce}\right) \times \frac{v}{m}
$$

In the above formula, $C_{0}$ and Ce were the initial concentration and equilibrium concentration of uranium solution $(\mathrm{mg} / \mathrm{L}) ; v$ was the volume of uranium solution (L), $m$ was the mass of adsorption material, and the unit was $g$.

2.5. Desorption Experiments. At the end of each adsorption experiment, the solution in the centrifuge tube was centrifuged to recover the adsorption material, which had adsorbed uranyl ions. The $\mathrm{CuFe}_{2} \mathrm{O}_{4} / \mathrm{PANI}$ nanocomposite was treated with ultrasound in $0.01 \mathrm{~mol} / \mathrm{L}$ hydrochloric acid solution for $5 \mathrm{~min}$ to remove the uranyl ions adsorbed in the adsorption material. The uranyl ions in the solution were then separated from $\mathrm{CuFe}_{2} \mathrm{O}_{4} / \mathrm{PANI}$ nanocomposite by centrifugation. The recovered nanocomposite was washed thoroughly before the adsorption experiment. In the repeated adsorption experiment, the concentration of uranyl ions in the residual solution after adsorption was determined by the micro uranium analyzer. In order to further determine the recyclability of $\mathrm{CuFe}_{2} \mathrm{O}_{4} / \mathrm{PANI}$ nanocomposite, five adsorption/elution cycles of uranyl ions were repeated in the experiments [44].

2.6. Adsorption Kinetics. Adsorption kinetics was an important method to study the adsorption efficiency of uranium. In order to further study the adsorption kinetics and mechanism of $\mathrm{CuFe}_{2} \mathrm{O}_{4} /$ PANI nanocomposite, the pseudosecond- order kinetic Equation (2) was used to fit the experimental data.

$$
\frac{t}{Q_{t}}=\frac{1}{K_{2} \cdot Q_{e}{ }^{2}}+\frac{t}{Q_{e}} .
$$

In the above formula, $Q_{e}$ was the adsorption capacity of adsorption material for uranyl ions at equilibrium time (mg/g); $Q_{t}$ was the adsorption capacity of the nanocomposite for uranyl ions reaction $t$ time $(\mathrm{mg} / \mathrm{g}) ; K_{2}$ was the rate constant of quasi second order kinetics $\left(\mathrm{g} \cdot \mathrm{mg}^{-1} \cdot \mathrm{min}^{-1}\right)$.

2.7. Equilibrium Isotherm Modelling. In order to better study the adsorption mechanism of the adsorption materials for uranyl ions, Langmuir and Freundlich isothermal adsorption models were used to fit the experimental data for uranium adsorption. Langmuir and Freundlich isothermal adsorption equations were shown in Formulas (3) and (4), respectively.

$$
\begin{aligned}
\frac{C_{e}}{q_{e}} & =\frac{1}{q_{\max } K_{L}}+\frac{C_{e}}{q_{\max }}, \\
\ln Q_{e} & =\ln K_{f}+\frac{\ln C_{e}}{n} .
\end{aligned}
$$

In the above formula, $C_{e}$ was the equilibrium concentration $(\mathrm{mg} / \mathrm{L}) ; q_{e}$ was the adsorption capacity $(\mathrm{mg} / \mathrm{g})$ of 


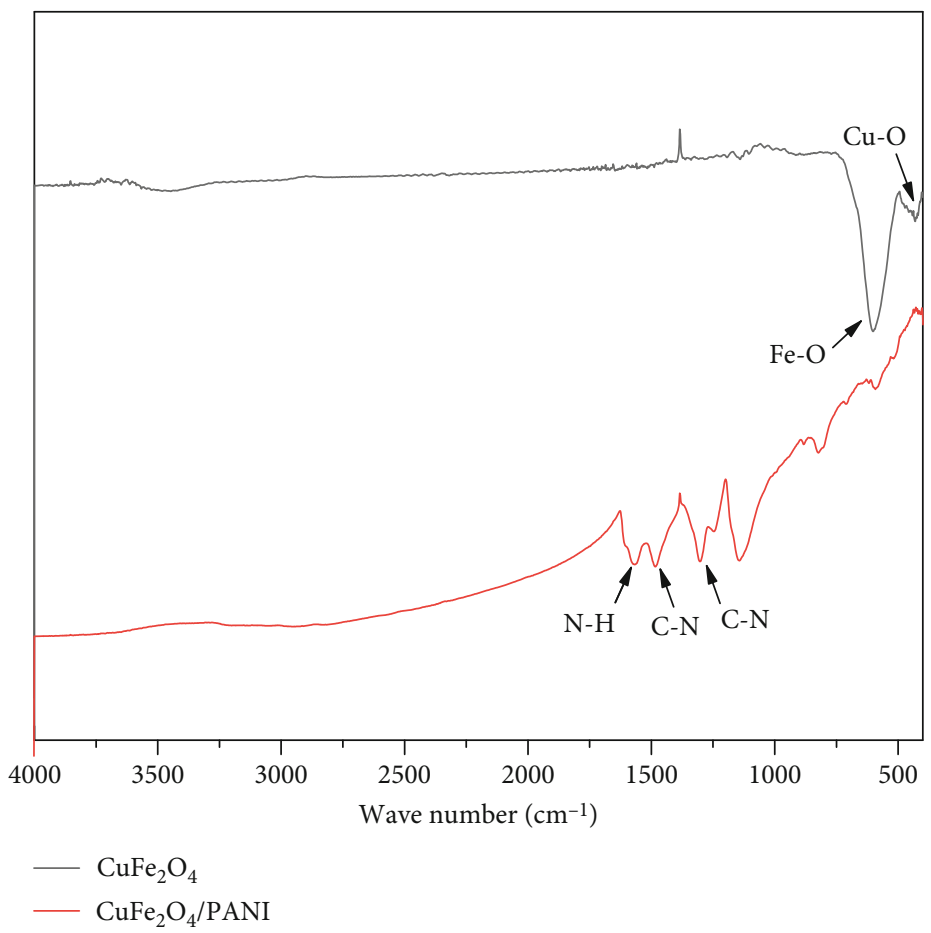

Figure 5: FTIR analysis of $\mathrm{CuFe}_{2} \mathrm{O}_{4}$ nanoparticles and $\mathrm{CuFe}_{2} \mathrm{O}_{4} / \mathrm{PANI}$ nanocomposite.

equilibrium time of uranyl ions; $q_{\max }$ was the maximum adsorption capacity $(\mathrm{mg} / \mathrm{g}) ; K_{L}$ was the adsorption isotherm parameter of Langmuir; $K_{f}$ represented adsorption strength $\left(\mathrm{mg}^{1-\mathrm{n}} \cdot \mathrm{g}^{-1} \cdot \mathrm{L}^{\mathrm{n}}\right) ; N$ was the adsorption capacity.

\section{Results and Discussion}

3.1. Characterization. The TEM images of magnetic $\mathrm{CuFe}_{2} \mathrm{O}_{4}$ nanoparticles and $\mathrm{CuFe}_{2} \mathrm{O}_{4} / \mathrm{PANI}$ nanocomposite are shown in Figure 1. As can be seen from the TEM images in Figure 1(a), $\mathrm{CuFe}_{2} \mathrm{O}_{4}$ nanoparticles have irregular spherical shape with good dispersion and a particle size of about $100 \mathrm{~nm}$. As shown in Figure 1(b), the generated polyaniline (PANI) coats with $\mathrm{CuFe}_{2} \mathrm{O}_{4}$ magnetic nanoparticles and forms a core-shell structure. The boundary between $\mathrm{CuFe}_{2} \mathrm{O}_{4} / \mathrm{PANI}$ nanocomposite is clear and presents regular distribution.

It shows in Figure 2 that the XRD pattern of magnetic $\mathrm{CuFe}_{2} \mathrm{O}_{4}$ nanoparticles and $\mathrm{CuFe}_{2} \mathrm{O}_{4} / \mathrm{PANI}$ nanocomposite are set from $10^{\circ}$ to $90^{\circ}$. According to the XRD pattern, the diffraction peak is consistent with the amorphous phase of polyaniline, and the characteristic peak of PANI is displayed at $24.2^{\circ}$. It can be seen from the XRD pattern of $\mathrm{CuFe}_{2} \mathrm{O}_{4}$ that the characteristic peak appears at $33.3^{\circ}$, and the diffraction peak is consistent with the square spinel of $\mathrm{CuFe}_{2} \mathrm{O}_{4}$, with good crystallinity [45, 46]. When PANI is successfully combined with $\mathrm{CuFe}_{2} \mathrm{O}_{4}$, it has no great influence on the crystal structure of $\mathrm{CuFe}_{2} \mathrm{O}_{4}$ nanoparticles.

As shown in Figure 3(a), there are five peaks at 288.5, $399.1,531.9,710.7$, and $950.2 \mathrm{eV}$, corresponding to $\mathrm{C} 1 \mathrm{~s}$,
$\mathrm{N} 1 \mathrm{~s}, \mathrm{O} 1 \mathrm{~s}, \mathrm{Fe} 2 \mathrm{p}$, and $\mathrm{Cu} 2 \mathrm{p}$, respectively. As shown in Figure 3(b), there are four peaks at 284.4, 532.1, 714.0, and $935.7 \mathrm{eV}$, corresponding to $\mathrm{C} 1 \mathrm{~s}, \mathrm{O} 1 \mathrm{~s}, \mathrm{Fe} 2 \mathrm{p}$, and $\mathrm{Cu} 2 \mathrm{p}$, respectively. It can be seen from the figure that a new peak of N1s with a binding energy of $400.7 \mathrm{eV}$ appears, which proves the existence of nitrogen atoms. It indicates that polyaniline has been successfully compounded on the magnetic $\mathrm{CuFe}_{2} \mathrm{O}_{4}$ nanoparticles.

Figure 4 shows the total pore volume of magnetic $\mathrm{CuFe}_{2} \mathrm{O}_{4}$ nanoparticles and $\mathrm{CuFe}_{2} \mathrm{O}_{4} /$ PANI nanocomposite of the $\mathrm{N}_{2}$ adsorption-desorption isotherm, which is shown in Table 1 for relevant parameters.

Compared with $\mathrm{CuFe}_{2} \mathrm{O}_{4}$ /PANI nanocomposites, the surface area of the material modified by polyaniline changes from 91.1 to $153 \mathrm{~m}^{2} / \mathrm{g}$, and the total pore volume and nitrogen adsorption capacity increase as the introduction of polyaniline. The porous core-shell structure formed by polyaniline coating on $\mathrm{CuFe}_{2} \mathrm{O}_{4}$ increases the pore diameter of the nanocomposite.

It shows in Figure 5 the IR spectra of magnetic $\mathrm{CuFe}_{2} \mathrm{O}_{4}$ nanoparticles and $\mathrm{CuFe}_{2} \mathrm{O}_{4} /$ PANI nanocomposite. According to the IR of $\mathrm{CuFe}_{2} \mathrm{O}_{4}$ nanoparticles, the peak at $433 \mathrm{~cm}^{-1}$ is the stretching vibration peak of $\mathrm{Cu}-\mathrm{O}$ bond, and the peak at $597 \mathrm{~cm}^{-1}$ is the stretching vibration peak of $\mathrm{Fe}$ $\mathrm{O}$ bond. This indicates that $\mathrm{CuFe}_{2} \mathrm{O}_{4}$ nanoparticles have been successfully synthesized. According to the spectrum of $\mathrm{CuFe}_{2} \mathrm{O}_{4} / \mathrm{PANI}$ nanocomposite, the peak at $1301 \mathrm{~cm}^{-1}$ represents $\mathrm{C}-\mathrm{N}$ vibration absorption peak, the peak at $1481 \mathrm{~cm}^{-1}$ is $\mathrm{C}-\mathrm{N}$ vibration absorption peak, and the peak at $1567 \mathrm{~cm}^{-1}$ is $\mathrm{N}-\mathrm{H}$ vibration absorption peak ([47-49]; Jawad, [50]). In the IR spectrum of $\mathrm{CuFe}_{2} \mathrm{O}_{4} / \mathrm{PANI}$ 


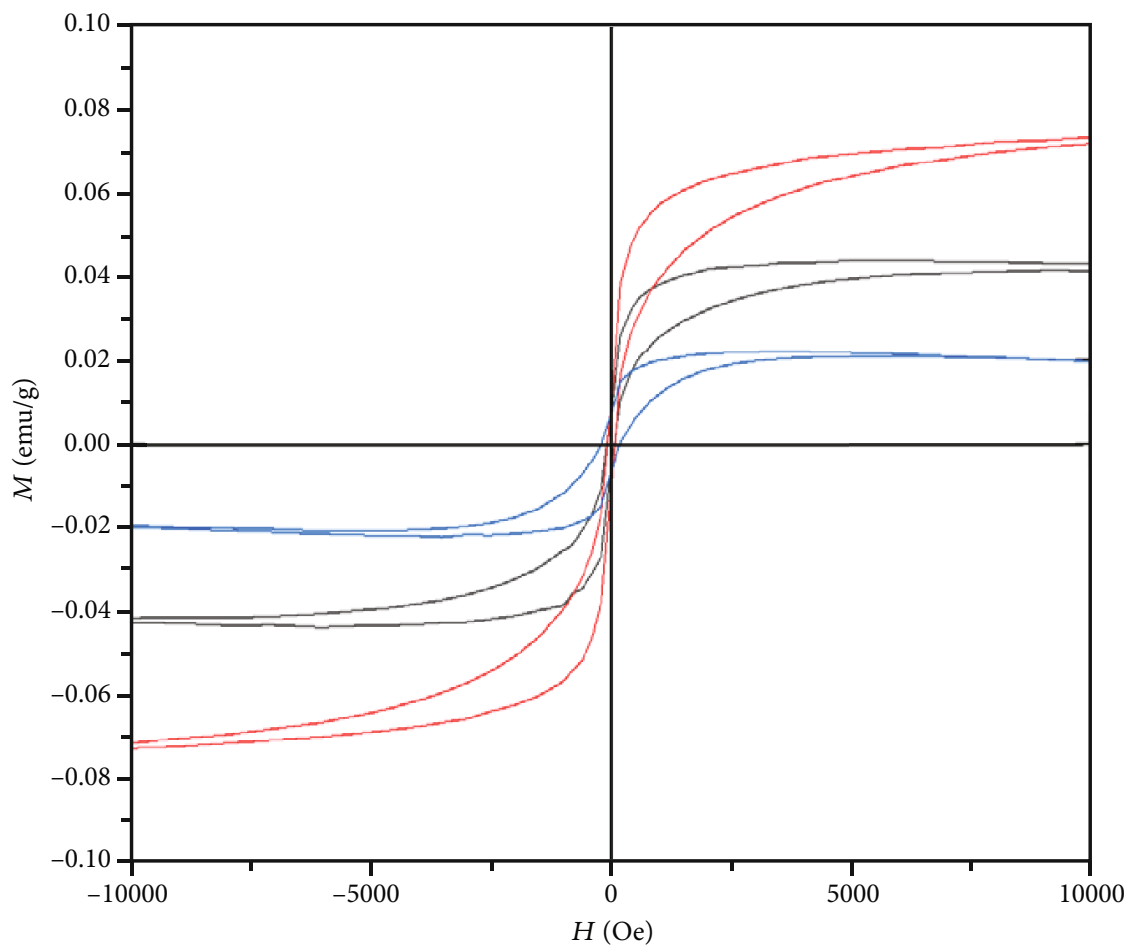

$-\mathrm{CuFe}_{2} \mathrm{O}_{4}$

$-\mathrm{CuFe}_{2} \mathrm{O}_{4} / \mathrm{PANI}$

_ Adsorbed $\mathrm{CuFe}_{2} \mathrm{O}_{4} / \mathrm{PANI}$

FiguRE 6: VSM curves of $\mathrm{CuFe}_{2} \mathrm{O}_{4}$ nanoparticles, $\mathrm{CuFe}_{2} \mathrm{O}_{4} @$ PANI nanocomposite, and adsorbed $\mathrm{CuFe}_{2} \mathrm{O}_{4} @$ PANI nanocomposite.

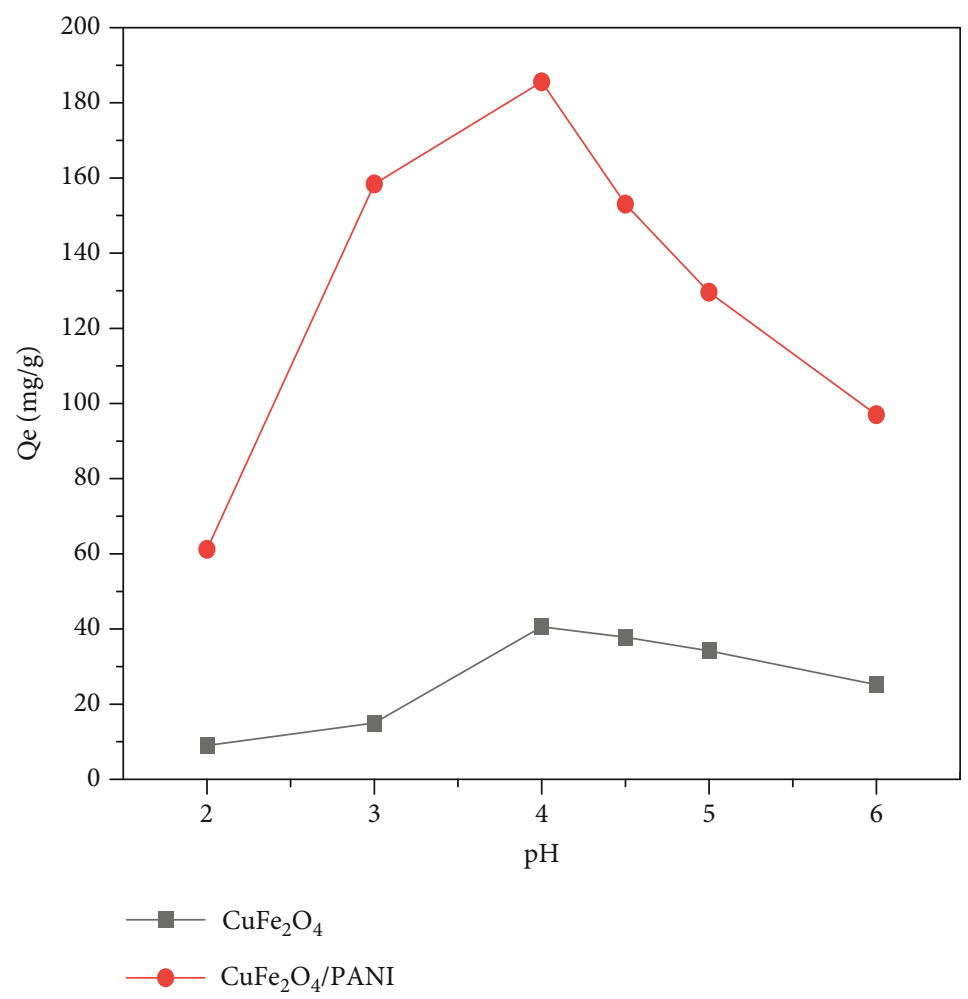

FIGURE 7: Effect of initial $\mathrm{pH}$ value of solution on the adsorption of $\mathrm{UO}_{2}{ }^{2+}$ by $\mathrm{CuFe}_{2} \mathrm{O}_{4}$ nanoparticles and $\mathrm{CuFe}_{2} \mathrm{O}_{4} / \mathrm{PANI}$ nanocomposite. 


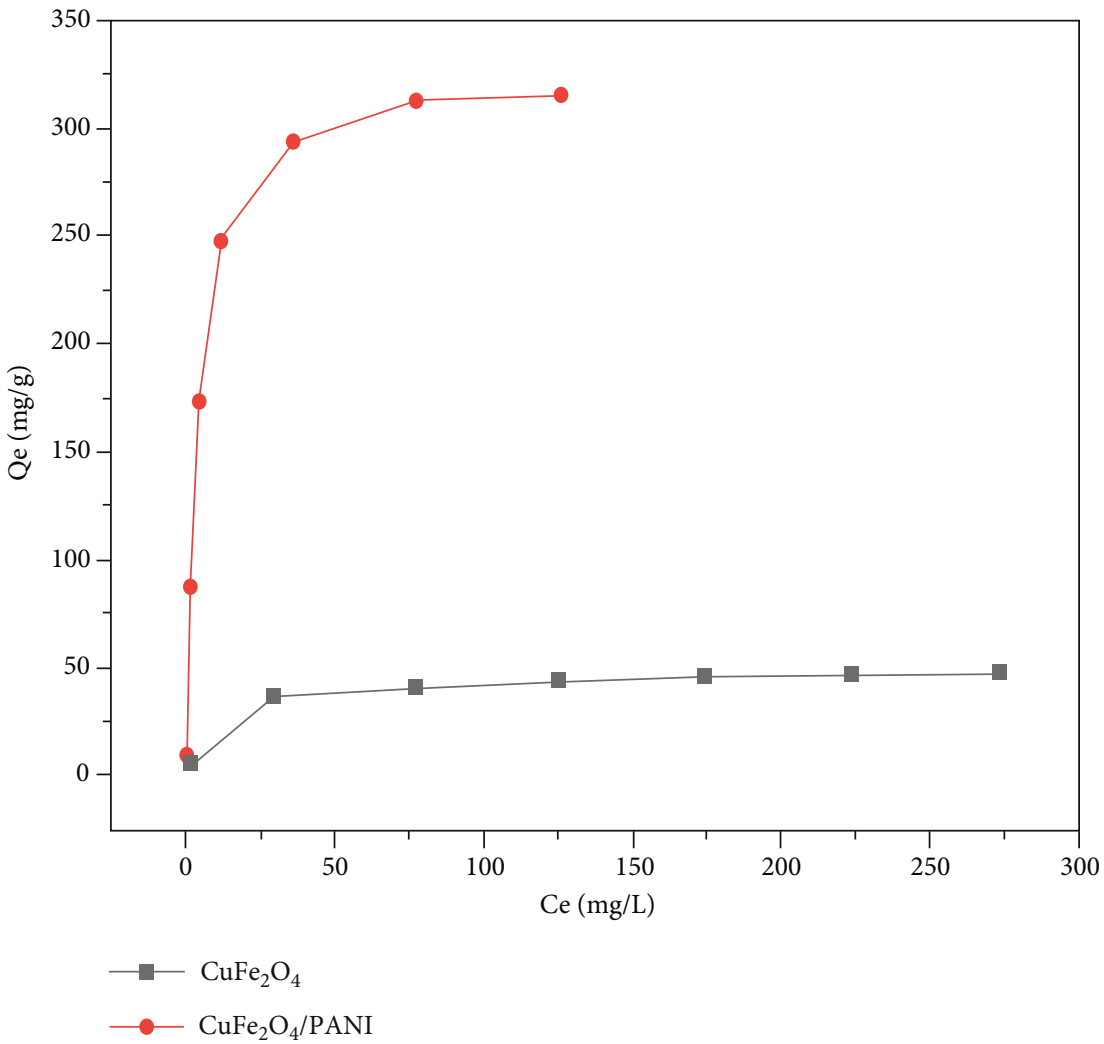

FIGURE 8: Effect of initial concentration value of solution on the adsorption of $\mathrm{UO}_{2}{ }^{2+}$ by $\mathrm{CuFe}_{2} \mathrm{O}_{4}$ nanoparticles and CuFe $\mathrm{O}_{4} / \mathrm{PANI}$ nanocomposite.

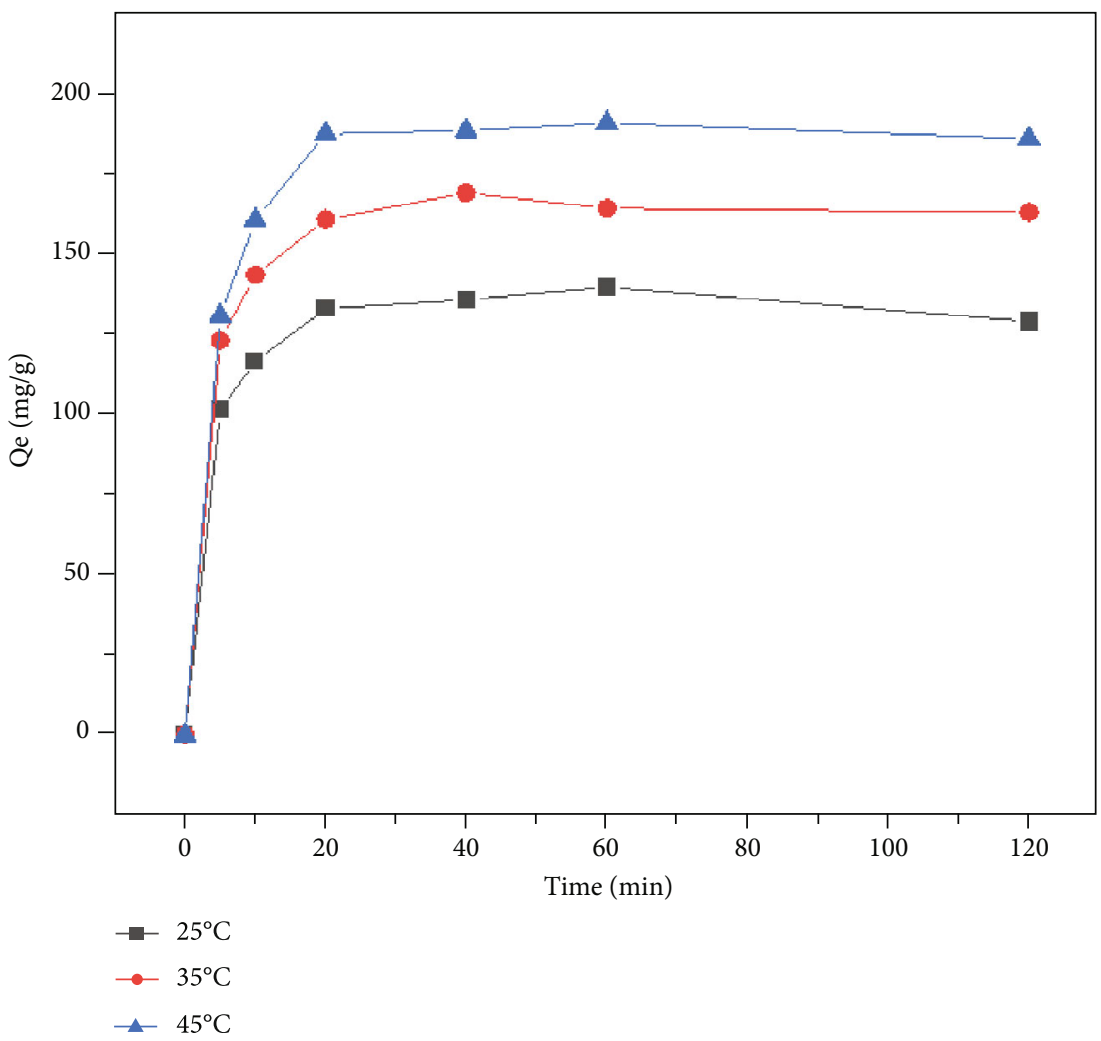

FIgURE 9: Effect of temperature and adsorption time value of solution on the adsorption of uranyl ions by $\mathrm{CuFe}_{2} \mathrm{O}_{4} / \mathrm{PANI}$ nanocomposite. 


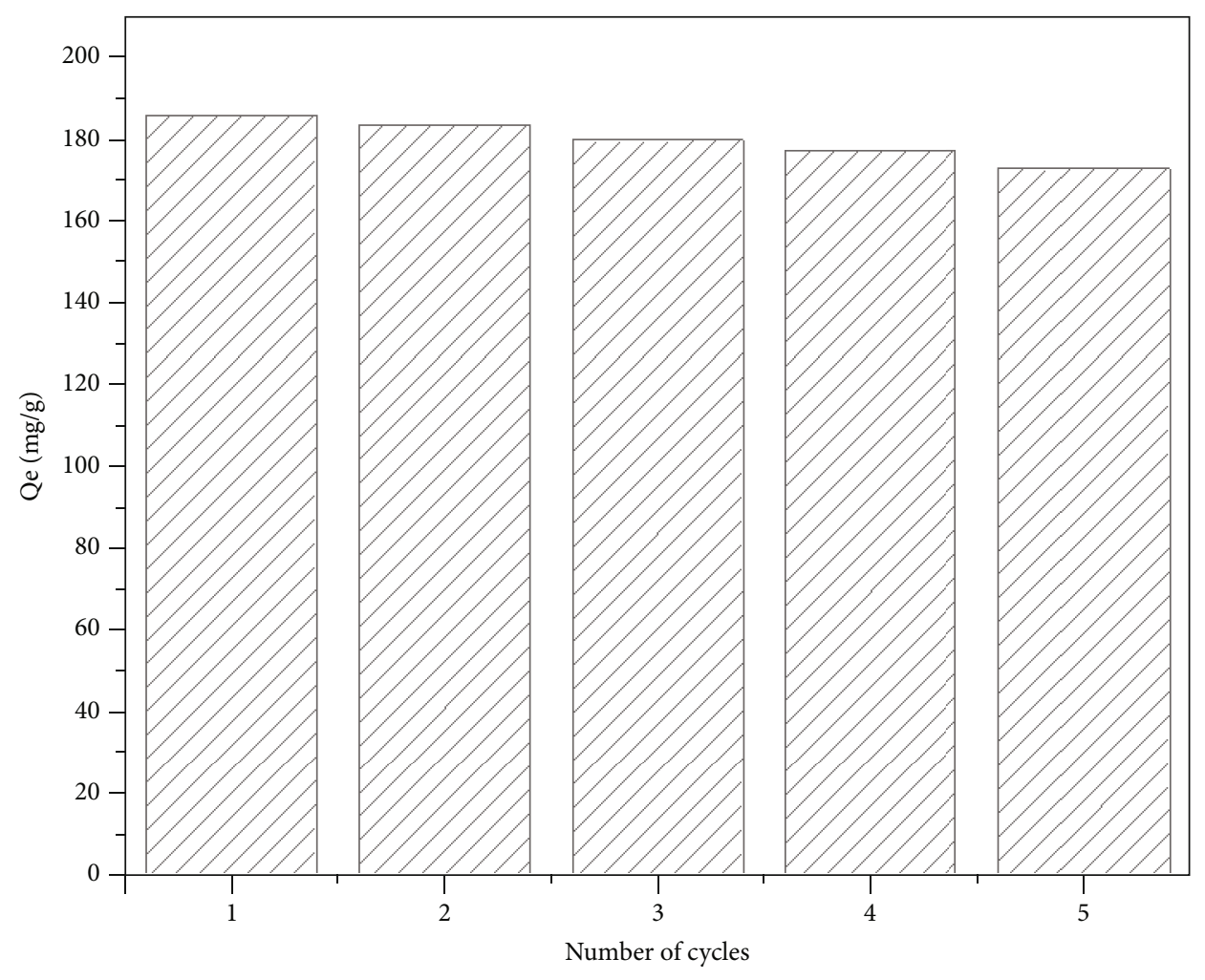

C/ $\mathrm{CuFe}_{2} \mathrm{O}_{4} / \mathrm{PANI}$

FIGURE 10: U (VI) adsorption efficiency on recycled $\mathrm{CuFe}_{2} \mathrm{O}_{4} / \mathrm{PANI}$ nanocomposite at each adsorption/desorption cycle.

nanocomposite, the characteristic peak of PANI can be seen, indicating the successful preparation of $\mathrm{CuFe}_{2} \mathrm{O}_{4} /$ PANI nanocomposite.

The magnetic properties of $\mathrm{CuFe}_{2} \mathrm{O}_{4}$ nanoparticles, $\mathrm{CuFe}_{2} \mathrm{O}_{4} / \mathrm{PANI}$ nanocomposite, and adsorbed $\mathrm{CuFe}_{2} \mathrm{O}_{4} /-$ PANI nanocomposite are characterized by vibrating sample magnetometer (VSM). The VSM diagram of them is shown in Figure 6.

As can be seen from Figure 6, the synthesized $\mathrm{CuFe}_{2} \mathrm{O}_{4}$ has magnetic properties $(0.04 \mathrm{emu} / \mathrm{g})$, but it is indeed very weak compared with other magnetic materials. It still appears " $\mathrm{S}$ " shaped hysteresis curve in $\mathrm{CuFe}_{2} \mathrm{O}_{4}$, which could be simply separated from a solution by external magnetic fields. After coating with PANI, the saturation magnetization value seems increased to a certain extent, but in fact, the actual value is very low, only as $0.07 \mathrm{emu} / \mathrm{g}$. The slight increase may be due to the residual free radicals during the polymerization process. After adsorption, the saturated magnetization intensity of $\mathrm{CuFe}_{2} \mathrm{O}_{4} @ \mathrm{PANI}$ nanocomposite is reduced to $0.02 \mathrm{emu} / \mathrm{g}$, which may be caused by the quenching of free radicals. It is close to its "intrinsic" value $\left(0.025 \mathrm{emu} / \mathrm{g}, 0.04 \mathrm{emu} / \mathrm{g} \times 0.625\right.$, the ratio of $\mathrm{CuFe}_{2} \mathrm{O}_{4}$ to PANI is 0.625 ).

3.2. Effect of pH on Adsorption of Uranyl Ions. Uranium has relatively active chemical properties. In alkaline media, uranium acid $\left(\mathrm{UO}_{2}{ }^{2-}\right)$ or diuranic acid $\left(\mathrm{U}_{2} \mathrm{O}_{7}{ }^{2-}\right)$ anions are easily produced. Uranium grinding cations $\left(\mathrm{UO}_{2}{ }^{2+}\right)$ tend to be produced in neutral and acidic media. The $\mathrm{pH}$ value of the solution not only affects the content of uranyl ions but also affects the adsorption performance of the adsorption material. Under the conditions of initial concentration of $100 \mathrm{~mol} / \mathrm{L}$, the adsorption time of $60 \mathrm{~min}$ and temperature of $25^{\circ} \mathrm{C}, \mathrm{CuFe}_{2} \mathrm{O}_{4} / \mathrm{PANI}$ nanocomposite was used to study the effect of initial $\mathrm{pH}$ of the solution on the adsorption capacity of uranyl ions, shown as in Figure 7.

In the initial solution, $\mathrm{pH}$ affects the adsorption experiment and the choice of $\mathrm{pH}$ range of $2 \sim 6$ in the uranium adsorption experiments, and it can be seen that the adsorption quantity of magnetic $\mathrm{CuFe}_{2} \mathrm{O}_{4}$ nanoparticles and $\mathrm{CuFe}_{2} \mathrm{O}_{4} / \mathrm{PANI}$ nanocomposite increases with the increase of $\mathrm{pH}$ value. At the condition of low $\mathrm{pH}$, the adsorption capacity of $\mathrm{CuFe}_{2} \mathrm{O}_{4} / \mathrm{PANI}$ nanocomposite as well as magnetic $\mathrm{CuFe}_{2} \mathrm{O}_{4}$ nanoparticles is low, and it is because there is a lot of $\mathrm{H}^{+}$that compete with uranyl ion adsorption. With the increase of $\mathrm{pH}$, the adsorption rate increases. If the $\mathrm{pH}$ value continues to increase, at a higher $\mathrm{pH}$ value, $\mathrm{UO}_{2}{ }^{2+}$ will hydrolyze to produce $\mathrm{UO}_{2}(\mathrm{OH})_{2}$ polynuclear hydroxide precipitation. So the $\mathrm{pH}$ value of 4 is selected for the following adsorption experiment.

As shown in Figure 7, the adsorption performance of $\mathrm{CuFe}_{2} \mathrm{O}_{4} / \mathrm{PANI}$ nanocomposite is higher than that of $\mathrm{CuFe}_{2} \mathrm{O}_{4}$ when the $\mathrm{pH}$ value is very low. When the $\mathrm{pH}$ value is in the range of 4 to 6 , the adsorption performance gradually decreases. 


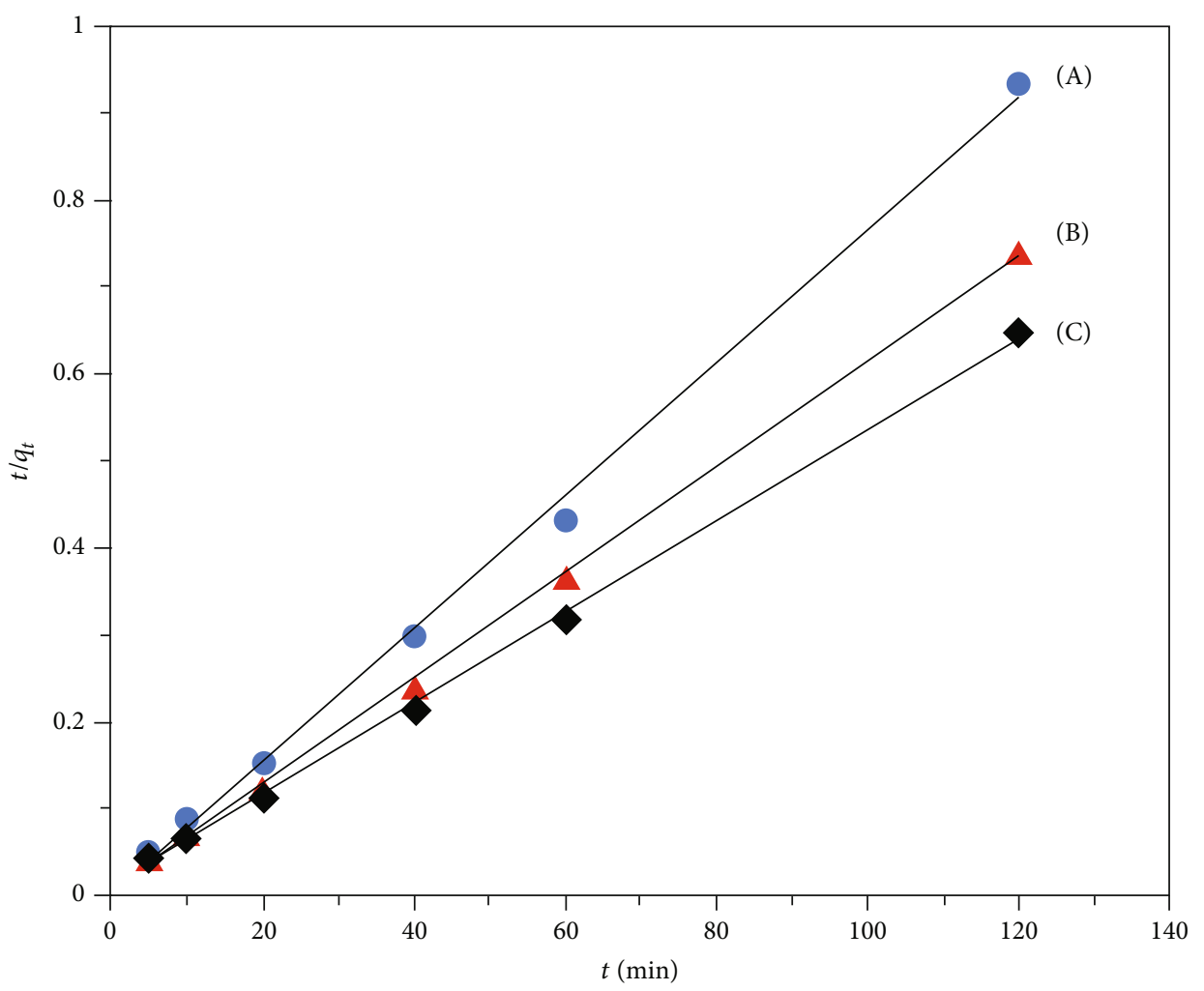

$25^{\circ} \mathrm{C}$

$35^{\circ} \mathrm{C}$

$45^{\circ} \mathrm{C}$

Figure 11: Pseudosecond-order kinetic curves of uranium adsorption on $\mathrm{CuFe}_{2} \mathrm{O}_{4} / \mathrm{PANI}$ nanocomposite at different temperatures: (A) $25^{\circ} \mathrm{C}$, (B) $35^{\circ} \mathrm{C}$, and (C) $45^{\circ} \mathrm{C}$, respectively.

3.3. Effect of Initial Concentration on Adsorption of Uranyl Ions. In order to evaluate the adsorbability of the materials and further to prove whether the introduction of amino groups could improve the adsorption properties. As can be seen from Figure 8, the adsorption capacity of $\mathrm{CuFe}_{2} \mathrm{O}_{4} /$ PANI nanocomposite and $\mathrm{CuFe}_{2} \mathrm{O}_{4}$ nanoparticles is relatively small when the initial concentration of uranyl ions is low, and the adsorption capacity goes up with the increase of the initial concentration. When the initial concentration is low, more amino groups would be coordinated with uranyl ions, and up to saturation point as the initial concentration increases gradually. So, the adsorption rate of uranyl ions in $\mathrm{CuFe}_{2} \mathrm{O}_{4} / \mathrm{PANI}$ nanocomposite is relatively high at low concentration. As a large number of nitrogen exist in $\mathrm{CuFe}_{2} \mathrm{O}_{4} / \mathrm{PANI}$ nanocomposite, the adsorption amount is as high as almost $320 \mathrm{mg} / \mathrm{g}$ under the condition of $\mathrm{Ce}<100 \mathrm{mg} / \mathrm{L}$ in its quick equilibrium state which indicates the excellent adsorption performance for uranyl ions adsorption.

3.4. Effect of Temperature and Adsorption Time on Adsorption of Uranyl Ions. It shows the adsorption capacity
TABLE 2: Kinetic parameters for uranium adsorption by $\mathrm{CuFe}_{2} \mathrm{O}_{4} /$ PANI nanocomposite.

\begin{tabular}{lccc}
\hline \multirow{2}{*}{$\left({ }^{\circ} \mathrm{C}\right)$} & \multicolumn{3}{c}{ Pseudosecond-order kinetics model } \\
& $q_{e}(\mathrm{mg} / \mathrm{g})$ & $K_{2}\left(\mathrm{~g} \cdot \mathrm{mg}^{-1} \cdot \mathrm{min}^{-1}\right)$ & $R^{2}$ \\
\hline 25 & 131.6 & 0.0064 & 0.9975 \\
35 & 163.9 & 0.0081 & 0.9994 \\
45 & 188.7 & 0.0055 & 0.9993 \\
\hline
\end{tabular}

curve of the adsorption material at temperatures of $25^{\circ} \mathrm{C}$, $35^{\circ} \mathrm{C}$, and $45^{\circ} \mathrm{C}$ with the adsorption time of $5 \sim 120 \mathrm{~min}$ in Figure 9. It can be observed that the adsorption capacity of the adsorbent is basically balanced at about $20 \mathrm{~min}$, and the adsorption equilibrium time is short. It can be seen from the results that the adsorption capacity of the adsorption materials is affected by the temperature. $\mathrm{CuFe}_{2} \mathrm{O}_{4} / \mathrm{PANI}$ nanocomposite adsorbing uranyl ions is the heat absorption process, the adsorption capacity is significantly lower when the temperature is low, and the adsorption capacity is greater when the temperature is high. This is mainly because with the 


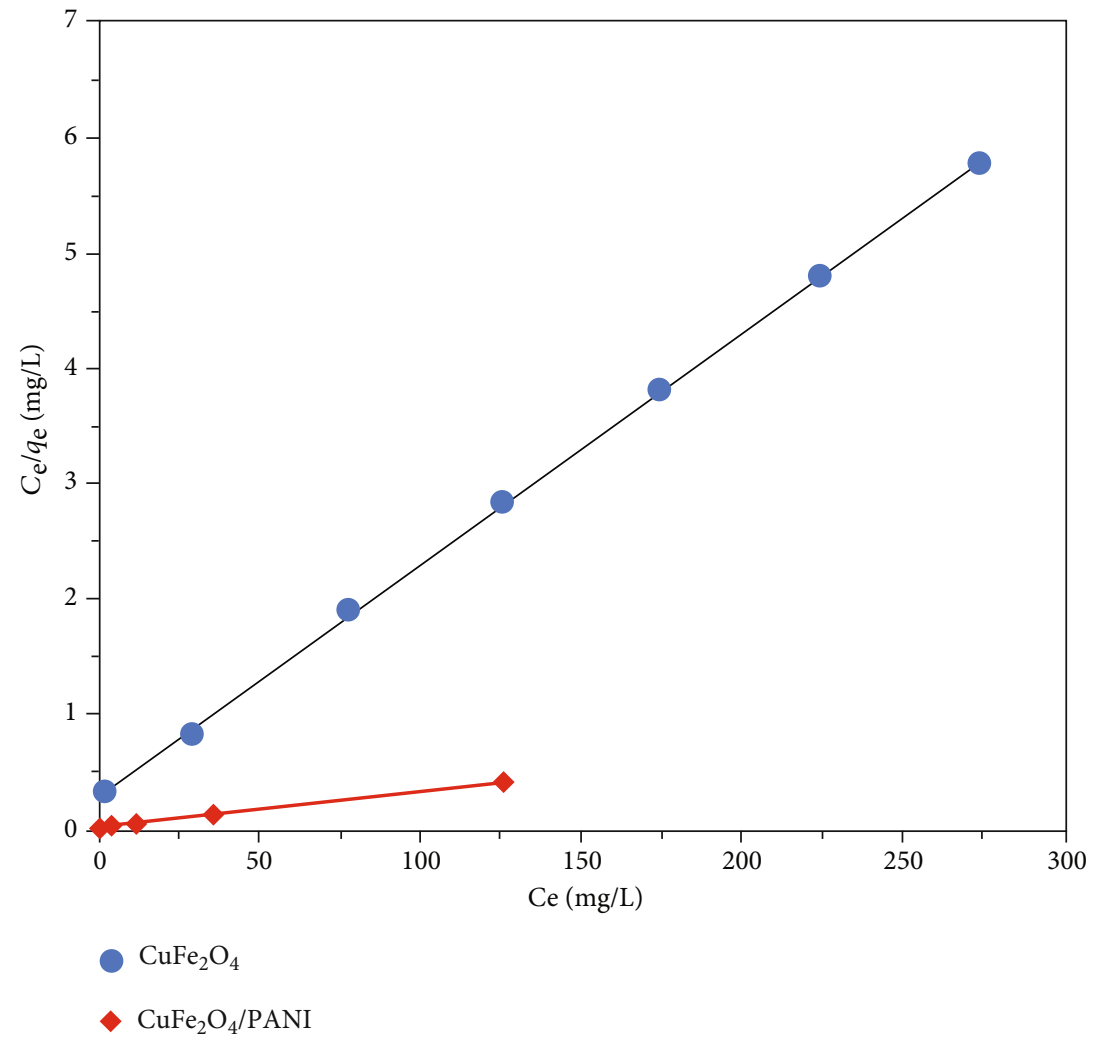

Figure 12: Fitting curves of Langmuir isotherm adsorption model for uranium on $\mathrm{CuFe}_{2} \mathrm{O}_{4}$ nanoparticles and $\mathrm{CuFe} \mathrm{O}_{4} / \mathrm{PANI}$ nanocomposite.

increase of adsorption temperature, the reaction activity of amino groups and uranyl ions of $\mathrm{CuFe}_{2} \mathrm{O}_{4}$ /PANI nanocomposite is enhanced, which is conducive to display its adsorption performance.

3.5. Regeneration. Recycling is an important index to evaluate the adsorption and regeneration performance of the adsorbents. It is of great significance to evaluate recycling in the practical application of adsorbents, which can not only save time but also reduce production costs. In order to evaluate the important index of recycling regeneration of $\mathrm{CuFe}_{2} \mathrm{O}_{4} /$ PANI nanocomposite, $0.01 \mathrm{~mol} / \mathrm{L} \mathrm{HCl}$ solution was used as the elution solution of regeneration.

More significantly, as reflected in Figure 10, the magnetic adsorption material is used to remove uranyl ions after regeneration. It shows the adsorption rate of $\mathrm{CuFe}_{2} \mathrm{O}_{4} / \mathrm{PANI}$ nanocomposite recovered in each adsorption/desorption cycle. The adsorption capacity of uranyl ions displays more than $170 \mathrm{mg} / \mathrm{g}$ during five consecutive cycles. The slight influence on the adsorption capacity proves that the $\mathrm{CuFe}_{2} \mathrm{O}_{4} / \mathrm{PANI}$ nanocomposite has a high reuse rate and displays its practical application prospect.

3.6. Adsorption Kinetics. Adsorption kinetics is an important method to study the adsorption efficiency of uranium. It can be seen from Figure 11 that $\mathrm{CuFe}_{2} \mathrm{O}_{4} / \mathrm{PANI}$ nanocomposite exhibits fast adsorption kinetics for uranyl ions.

It can be seen from Figure 11 and Table 2 that both adsorption capacity and reaction rate are affected by temper- ature. The quasisecond-order kinetic model to calculate the actual value theory adsorption capacity is closed to the experiment, and it shows that quasisecond-order kinetic model fits the linear correlation coefficient.

The correlation coefficient $R^{2}$ is more than 0.99 ; therefore, the quasisecond-order kinetic model can describe the adsorption behavior of $\mathrm{CuFe}_{2} \mathrm{O}_{4} / \mathrm{PANI}$ nanocomposite for uranyl ions.

3.7. Equilibrium Isotherm Modelling. In order to better study the adsorption mechanism of $\mathrm{CuFe}_{2} \mathrm{O}_{4}$ and $\mathrm{CuFe}_{2} \mathrm{O}_{4} / \mathrm{PANI}$ nanocomposite for uranyl ions, Langmuir and Freundlich isothermal adsorption models are used to fit the experimental data for uranyl ions adsorption of $\mathrm{CuFe}_{2} \mathrm{O}_{4}$ and $\mathrm{CuFe}_{2} \mathrm{O}_{4} /-$ PANI nanocomposite, respectively.

As shown in Figures 12 and 13 and Table 3, the correlation coefficient $R^{2}$ of the Langmuir model is greater than 0.999. The experimental data are closed to the theoretical model, indicating that it can well describe the adsorption process of uranyl ions by $\mathrm{CuFe}_{2} \mathrm{O}_{4} /$ PANI nanocomposite. The isotherm is best described by Langmuir adsorption model in the process of adsorption kinetics.

The maximum adsorption capacity for uranyl ions is about $322.6 \mathrm{mg} / \mathrm{g}$, which is higher than many other types of uranyl ion adsorbents and has good adsorption performance comparing with other similar work [13].

It lists the comparison of maximum adsorption capacity $\left(q_{m}\right)$ of $\mathrm{U}(\mathrm{VI})$ using various adsorbents in Table $4[49,51-$ 


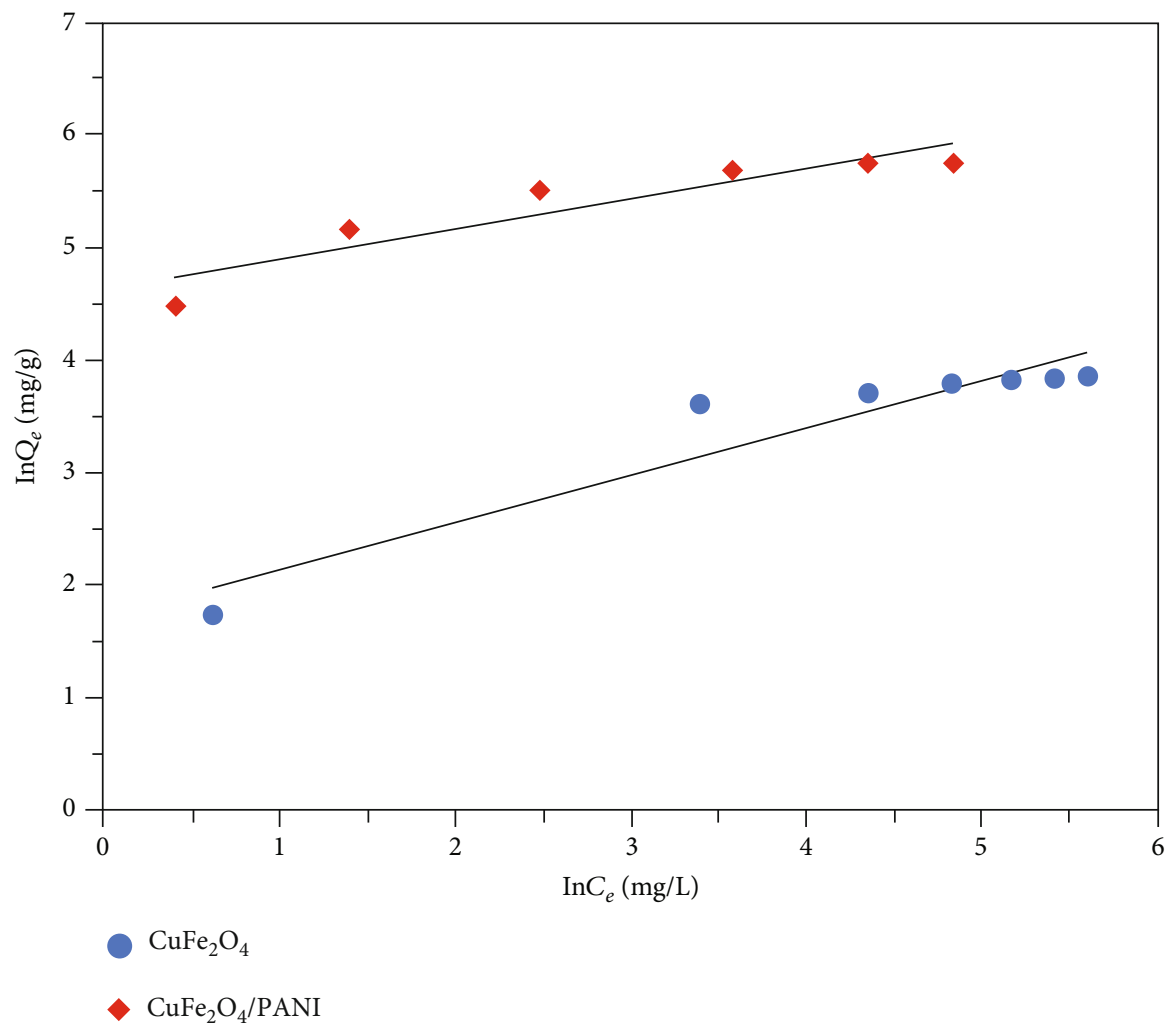

Figure 13: Fitting curves of Freundlich isotherm adsorption model for uranium on $\mathrm{CuFe}_{2} \mathrm{O}_{4}$ nanoparticles and CuFe $\mathrm{O}_{4} / \mathrm{PANI}$ nanocomposite.

TABle 3: Langmuir and Freundlich isotherm adsorption constants of $\mathrm{CuFe}_{2} \mathrm{O}_{4}$ nanoparticles and $\mathrm{CuFe}_{2} \mathrm{O}_{4} / \mathrm{PANI}$ nanocomposite for uranium adsorption.

\begin{tabular}{|c|c|c|c|c|c|c|}
\hline \multirow{2}{*}{ Adsorbent type } & \multicolumn{3}{|c|}{ Langmuir } & \multicolumn{3}{|c|}{ Freundlich } \\
\hline & $K_{L}(\mathrm{mg} / \mathrm{L})$ & $q_{m}(\mathrm{mg} / \mathrm{g})$ & $R^{2}$ & $K_{f}\left(\mathrm{mg}^{1-\mathrm{n}} \cdot \mathrm{g}^{-1} \cdot \mathrm{L}^{\mathrm{n}}\right)$ & $n$ & $R^{2}$ \\
\hline $\mathrm{CuFe}_{2} \mathrm{O}_{4}$ & 0.0709 & 49.50 & 0.9996 & 5.57 & 2.38 & 0.8992 \\
\hline $\mathrm{CuFe}_{2} \mathrm{O}_{4} / \mathrm{PANI}$ & 0.310 & 322.6 & 0.9998 & 102 & 3.74 & 0.8545 \\
\hline
\end{tabular}

TABle 4: Comparison of adsorption capacity of $\mathrm{CuFe}_{2} \mathrm{O}_{4} / \mathrm{PANI}$ nanocomposite with different adsorbents.

\begin{tabular}{lcc}
\hline Adsorbents & $\begin{array}{c}\text { Maximum adsorption } \\
\text { capacity }\end{array}$ & Ref \\
\hline $\begin{array}{l}\text { Polypropylene (PP) } \\
\text { nanofibers }\end{array}$ & $83.24 \mathrm{mg} / \mathrm{g}$ & {$[55]$} \\
$\mathrm{Ap}-\mathrm{ZnO} / \mathrm{PSBN}$ & $139.8 \mathrm{mg} / \mathrm{g}$ & {$[51]$} \\
$\mathrm{AM} / \mathrm{PDA}$ & $250.7 \mathrm{mg} / \mathrm{g}$ & {$[54]$} \\
$\mathrm{MoS}_{2}$-IP6 NRA/CC & $183.3 \mathrm{mg} / \mathrm{g}$ & {$[53]$} \\
$\mathrm{SBA}^{-15 / N H S O} \mathrm{H}$ & $140.5 \mathrm{mg} / \mathrm{g}$ & {$[52]$} \\
$\mathrm{CuFe}_{2} \mathrm{O}_{4} / \mathrm{PANI}$ & $322.6 \mathrm{mg} / \mathrm{g}$ & This \\
& & work \\
\hline
\end{tabular}

55]. The maximum adsorption capacity of $\mathrm{CuFe}_{2} \mathrm{O}_{4} / \mathrm{PANI}$ on U(VI) was higher than that of other adsorbents as shown in Table 4.
3.8. Magnetic Validation Study. As shown in Figure 13, the magnetic verification experiment results show that the synthesized $\mathrm{CuFe}_{2} \mathrm{O}_{4} / \mathrm{PANI}$ nanocomposite has good magnetic properties, which ensures that the adsorption material can be easily separated from the cleaning medium. It shows in the magnetic verification experiment the ideal magnetism under the action of magnet in Figure 14(a). On this basis, its dispersion is further verified by ultrasound. Results as shown in Figure $14(\mathrm{~b}), \mathrm{CuFe}_{2} \mathrm{O}_{4} / \mathrm{PANI}$ magnetic nanocomposite has good dispersion after ultrasound, indicating that the particles are uniform and of good particle size. In the magnetic separation verification experiment of $\mathrm{SiO}_{2}$ turbidity liquid, it has sufficient magnetic response to make it separated from the mixture immediately under the action of the external magnetic field. Therefore, $\mathrm{CuFe}_{2} \mathrm{O}_{4} / \mathrm{PANI}$ nanocomposite has been easily to be enriched under the action of magnetic field and can be used for magnetic separation, recovery, and reuse for its practical application prospect. 


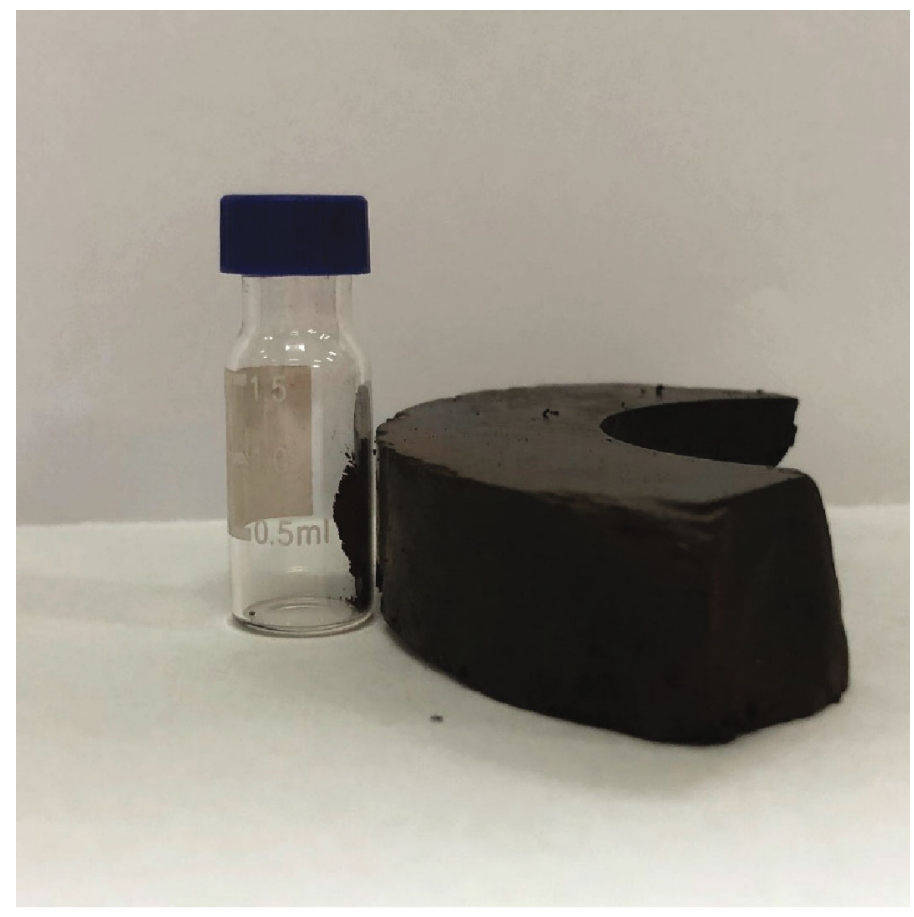

(a)

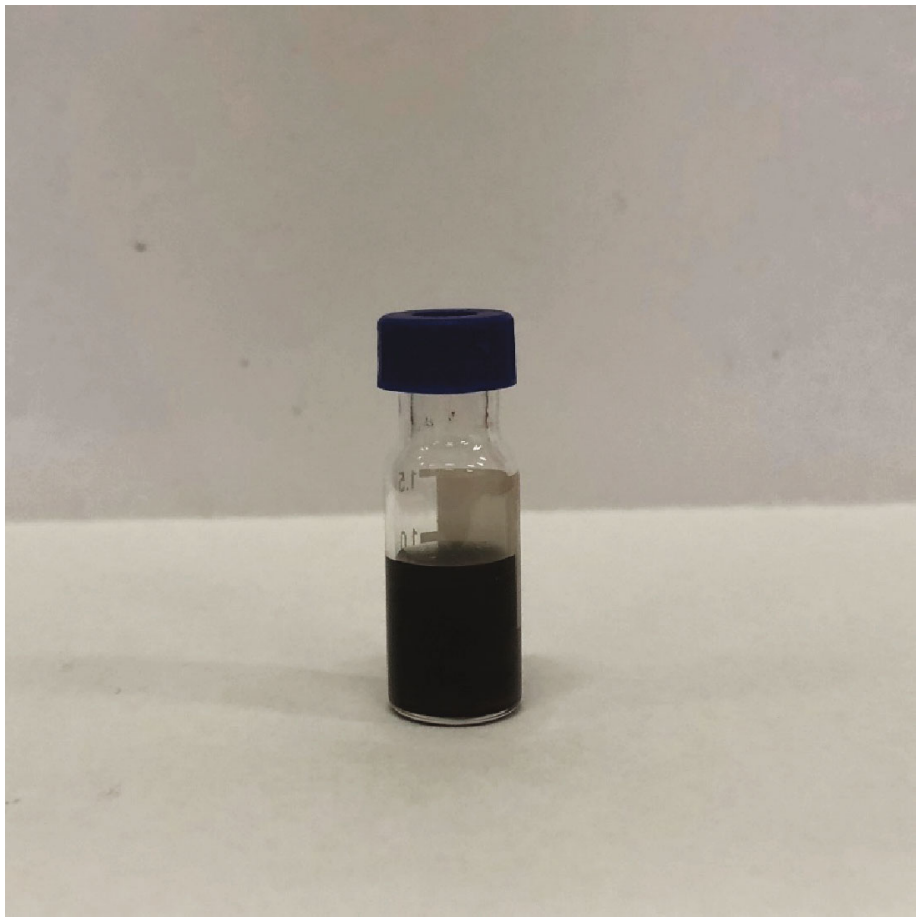

(b)

FIgUre 14: Pictures of magnetic validation of $\mathrm{CuFe}_{2} \mathrm{O}_{4} / \mathrm{PANI}$ nanocomposite.

\section{Conclusion}

In this study, a novel magnetic adsorption material $\mathrm{CuFe}_{2} \mathrm{O}_{4} / \mathrm{PANI}$ nanocomposite has been successfully prepared by polyaniline (PANI) combined with $\mathrm{CuFe}_{2} \mathrm{O}_{4}$ nanoparticles in situ polymerization and is used for the adsorption of radioactive uranium in an aqueous solution. When $\mathrm{pH}=$
4.0, magnetic $\mathrm{CuFe}_{2} \mathrm{O}_{4} / \mathrm{PANI}$ nanocomposite has the best adsorption effect, and the maximum adsorption capacity for uranyl ions is $322.6 \mathrm{mg} / \mathrm{g}$. The introduction of amino functional groups makes the adsorption performance of $\mathrm{CuFe}_{2} \mathrm{O}_{4} / \mathrm{PANI}$ nanoparticles much higher than that of $\mathrm{CuFe}_{2} \mathrm{O}_{4}$ nanoparticles. The adsorption process is consistent with the quasisecond-order kinetic equation and Langmuir 
isothermal adsorption model, which indicates that the adsorption process is mainly chemisorption and monolayer adsorption. The recovery experiments show that magnetic $\mathrm{CuFe}_{2} \mathrm{O}_{4} / \mathrm{PANI}$ nanocomposite has good repeatability and stability due to its magnetic properties. After five cycles of recovery, the adsorption capacity of magnetic $\mathrm{CuFe}_{2} \mathrm{O}_{4} /-$ PANI nanocomposite would be maintained at more than $170 \mathrm{mg} / \mathrm{g}$, which is expected to be a promising renewable adsorption material.

\section{Data Availability}

The datasets generated during and/or analysed during the current study are available from the corresponding author on reasonable request.

\section{Additional Points}

Highlights. A novel magnetic adsorption material $\mathrm{CuFe}_{2} \mathrm{O}_{4} /-$ PANI nanocomposite has been synthesized by polyaniline (PANI) combined with $\mathrm{CuFe}_{2} \mathrm{O}_{4}$ in situ polymerization. The prepared $\mathrm{CuFe}_{2} \mathrm{O}_{4} / \mathrm{PANI}$ nanocomposite exhibits extremely high maximum adsorption capacity $(322.6 \mathrm{mg} / \mathrm{g})$ for uranyl ion in wastewater at a $\mathrm{pH}$ of 4 and can quickly reach the equilibrium state. The magnetic $\mathrm{CuFe}_{2} \mathrm{O}_{4} / \mathrm{PANI}$ displays stable adsorption performance for uranyl ions after five cycles of recovery, which indicates it possesses good recovery due to its magnetism and excellent regeneration ability for reusability.

\section{Conflicts of Interest}

The authors declare that they have no conflicts of interest.

\section{References}

[1] M. J. Manos and M. G. Kanatzidis, "Layered metal sulfides capture uranium from seawater," Journal of the American Chemical Society, vol. 134, no. 39, pp. 16441-16446, 2012.

[2] S. Chu and A. Majumdar, "Opportunities and challenges for a sustainable energy future," Nature, vol. 488, no. 7411, pp. 294303, 2012.

[3] R. L. Kathren and S. Y. Tolmachev, "The US Transuranium and Uranium Registries (USTUR): a five-decade follow-up of plutonium and uranium workers," Health Physics, vol. 117, no. 2, pp. 118-132, 2019.

[4] D. Ma, J. Wei, Y. Zhao, Y. Chen, and S. Tang, "The removal of uranium using novel temperature sensitive urea-formaldehyde resin: adsorption and fast regeneration," Science of the Total Environment, vol. 735, p. 139399, 2020.

[5] T. ÖZdemir and A. Usanmaz, "Use of poly(methyl methacrylate) in radioactive waste management: II. Monte Carlo simulations," Progress in Nuclear Energy, vol. 51, no. 8, pp. 845-848, 2009.

[6] A. Mellah, S. Chegrouche, and M. Barkat, "The precipitation of ammonium uranyl carbonate (AUC): thermodynamic and kinetic investigations," Hydrometallurgy, vol. 85, no. 2-4, pp. 163-171, 2007.

[7] M. M. Chen, Z. Li, J. H. Li, J. Li, Q. Li, and L. Zhang, “The extraction of uranium using graphene aerogel loading organic solution," Talanta, vol. 166, pp. 284-291, 2017.
[8] X. Y. Zheng, X. Y. Wang, Y. H. Shen, X. Lu, and T. S. Wang, "Biosorption and biomineralization of uranium(VI) by_Saccharomyces cerevisiae_ -crystal formation of chernikovite," Chemosphere, vol. 175, pp. 161-169, 2017.

[9] M. G. Torkabad, A. R. Keshtkar, and S. J. Safdari, “Comparison of polyethersulfone and polyamide nanofiltration membranes for uranium removal from aqueous solution," Progress in Nuclear Energy, vol. 94, pp. 93-100, 2017.

[10] J. De Decker, K. Folens, J. De Clercq et al., "Ship-in-a-bottle CMPO in MIL-101(Cr) for selective uranium recovery from aqueous streams through adsorption," Journal of Hazardous Materials, vol. 335, pp. 1-9, 2017.

[11] S. A. Kirillov, T. V. Lisnycha, and O. I. Pendelyuk, "Appraisal of mixed amorphous manganese oxide/titanium oxide sorbents for the removal of strontium-90 from solutions, with special reference to Savannah river site and chernobyl radioactive waste simulants," Adsorption Science \& Technology, vol. 24, no. 10, pp. 895-906, 2006.

[12] F. Liu, S. Song, G. Cheng, W. Xiong, L. Shi, and Y. Zhang, "MIL-101(Cr) metal-organic framework functionalized with tetraethylenepentamine for potential removal of uranium (VI) from waste water," Adsorption Science \& Technology, vol. 36, no. 7-8, pp. 1550-1567, 2018.

[13] A. A. Alqadami, M. Naushad, Z. A. Alothman, and A. A. Ghfar, "Novel metal-organic framework (MOF) based composite material for the sequestration of $\mathrm{U}(\mathrm{VI})$ and $\mathrm{Th}(\mathrm{IV})$ metal ions from aqueous environment," ACS Applied Materials \& Interfaces, vol. 9, no. 41, pp. 36026-36037, 2017.

[14] M. d'Halluin, J. Rull-Barrull, G. Bretel, C. Labrugère, E. Le Grognec, and F.-X. Felpin, "Chemically modified cellulose filter paper for heavy metal remediation in water," ACS Sustainable Chemistry \& Engineering, vol. 5, no. 2, pp. 1965-1973, 2017.

[15] A. Z. Ekoa Bessa, G. Ngueutchoua, A. Kwewouo Janpou et al., "Heavy metal contamination and its ecological risks in the beach sediments along the Atlantic Ocean (Limbe coastal fringes, Cameroon)," Earth Systems and Environment, pp. 112, 2020.

[16] S. Rangabhashiyam and P. Balasubramanian, "Characteristics, performances, equilibrium and kinetic modeling aspects of heavy metal removal using algae," Bioresource Technology Reports, vol. 5, pp. 261-279, 2019.

[17] G. Sharma and M. Naushad, "Adsorptive removal of noxious cadmium ions from aqueous medium using activated carbon/zirconium oxide composite: isotherm and kinetic modelling," Journal of Molecular Liquids, vol. 310, p. 317, 2020.

[18] X. L. Liu, H. W. Pang, X. W. Liu et al., "Orderly porous covalent organic frameworks-based materials: superior adsorbents for pollutants removal from aqueous solutions," The Innovation, vol. 2, no. 1, p. 100076, 2021.

[19] A. Zhang, G. Uchiyama, and T. Asakura, "Dynamic-state adsorption and elution behaviour of uranium (VI) ions from seawater by a fibrous and porous adsorbent containing amidoxime chelating functional groups," Adsorption Science \& Technology, vol. 21, no. 8, pp. 761-773, 2003.

[20] W. H. Zou, J. Y. Song, K. Li, and R. Han, "Use of manganese oxide-coated sand for the adsorption of uranium(VI) ions from aqueous solution using a column mode," Adsorption Science \& Technology, vol. 28, no. 4, pp. 313-325, 2010.

[21] W. Wongjaikham, D. Wongsawaeng, P. Hosemann, C. Kanokworakan, and V. Ratnitsai, "Enhancement of uranium recovery from seawater using amidoximated polymer 
gel synthesized from radiation-polymerization and crosslinking of acrylonitrile and methacrylic acid monomers," Journal of Environmental Chemical Engineering, vol. 6, no. 2, pp. 2768-2777, 2018.

[22] J. L. Wu, K. Tian, and J. L. Wang, "Adsorption of uranium (VI) by amidoxime modified multiwalled carbon nanotubes," Progress in Nuclear Energy, vol. 106, pp. 79-86, 2018.

[23] P. Zong, X. Wu, J. Gou, X. Lei, D. Liu, and H. Deng, "Immobilization and recovery of uranium(VI) using Na-bentonite from aqueous medium: equilibrium, kinetics and thermodynamics studies," Journal of Molecular Liquids, vol. 209, pp. 358-366, 2015.

[24] T. S. Anirudhan, G. S. Lekshmi, and F. Shainy, "Synthesis and characterization of amidoxime modified chitosan/bentonite composite for the adsorptive removal and recovery of uranium from seawater," Journal of Colloid and Interface Science, vol. 534, pp. 248-261, 2019.

[25] S. Acharya, D. K. Padhi, and K. M. Parida, "Visible light driven $\mathrm{LaFeO}_{3}$ nano sphere/RGO composite photocatalysts for efficient water decomposition reaction," Catalysis Today, vol. 353, pp. 220-231, 2020.

[26] A. Jawed, V. Saxena, and L. M. Pandey, "Engineered nanomaterials and their surface functionalization for the removal of heavy metals: a review," Journal of Water Process Engineering, vol. 33, article 101009, 2020.

[27] B. Ou, J. Wang, Y. Wu, S. Zhao, and Z. Wang, "Efficient removal of $\mathrm{Cr}(\mathrm{VI})$ by magnetic and recyclable calcined CoFe$\mathrm{LDH} / \mathrm{g}-\mathrm{C}_{3} \mathrm{~N}_{4}$ via the synergy of adsorption and photocatalysis under visible light," Chemical engineering journal, vol. 380, p. $122600,2020$.

[28] D. Serantes, R. Chantrell, H. Gavilán et al., "Anisotropic magnetic nanoparticles for biomedicine: bridging frequency separated AC-field controlled domains of actuation," Physical Chemistry Chemical Physics, vol. 20, no. 48, pp. 3044530454, 2018.

[29] Y. P. Chang, C. L. Ren, J. C. Qu, and X. G. Chen, "Preparation and characterization of $\mathrm{Fe}_{3} \mathrm{O}_{4}$ /graphene nanocomposite and investigation of its adsorption performance for aniline and _p_ -chloroaniline," Applied Surface Science, vol. 261, pp. 504-509, 2012.

[30] D. Lv, J. Zhou, Z. Cao et al., "Mechanism and influence factors of chromium(VI) removal by sulfide-modified nanoscale zerovalent iron," Chemosphere, vol. 224, pp. 306-315, 2019.

[31] J. Zhang, S. Zhai, S. Li et al., "Pb (II) removal of $\mathrm{Fe}_{3} \mathrm{O}_{4} @ \mathrm{SiO}_{2}$ $\mathrm{NH}_{2}$ core-shell nanomaterials prepared via a controllable solgel process," Chemical Engineering Journal, vol. 215, pp. 461-471, 2013.

[32] A. H. Jawad, N. N. A. Malek, A. S. Abdulhameed, and R. Razuan, "Synthesis of magnetic chitosan-fly $\mathrm{Ash} / \mathrm{Fe} 3 \mathrm{O} 4 \mathrm{com}-$ posite for adsorption of reactive orange 16 dye: optimization by Box-Behnken design," Journal of Polymers and the Environment, vol. 28, no. 3, pp. 1068-1082, 2020.

[33] A. E. I.-A. HM, R. S. Farag, and S. A. Abdel-Gawad, "Removal of contaminant metformin from water by using Ficus benjamina zero-valent iron/copper nanoparticles," Nanotechnology for Environmental Engineering, vol. 5, no. 3, p. 23, 2020.

[34] H. M. H. Gad and M. A. Youssef, "Sorption behavior of Eu(III) from an aqueous solution onto modified hydroxyapatite: kinetics, modeling and thermodynamics," Environmental Technology, vol. 39, no. 20, pp. 2583-2596, 2018.
[35] R. Quiroga-Flores, A. Noshad, R. Wallenberg, and L. Önnby, "Adsorption of cadmium by a high-capacity adsorbent composed of silicate-titanate nanotubes embedded in hydrogel chitosan beads," Environmental Technology, vol. 41, no. 23, pp. 3043-3054, 2020.

[36] Q. Li, L. Sun, Y. Zhang, Y. Qian, and J. Zhai, "Characteristics of equilibrium, kinetics studies for adsorption of $\mathrm{Hg}(\mathrm{II})$ and Cr(VI) by polyaniline/humic acid composite," Desalination, vol. 266, no. 1-3, pp. 188-194, 2011.

[37] M. Bhaumik, A. Maity, V. V. Srinivasu, and M. S. Onyango, "Removal of hexavalent chromium from aqueous solution using polypyrrole-polyaniline nanofibers," Chemical Engineering Journal, vol. 181, pp. 323-333, 2012.

[38] D. D. Shao, C. L. Chen, and X. K. Wang, "Application of polyaniline and multiwalled carbon nanotube magnetic composites for removal of $\mathrm{Pb}$ (II)," Chemical Engineering Journal, vol. 185, pp. 144-150, 2012.

[39] M. Ben Ali, F. Y. Wang, R. Boukherroub, W. Lei, and M. Xia, "Phytic acid-doped polyaniline nanofibers-clay mineral for efficient adsorption of copper (II) ions," Journal of Colloid and Interface Science, vol. 553, pp. 688-698, 2019.

[40] R. B. Gapusan and M. D. L. Balela, "Adsorption of anionic methyl orange dye and lead(II) heavy metal ion by polyaniline-kapok fiber nanocomposite," Materials Chemistry and Physics, vol. 243, p. 122682, 2020.

[41] S. A. Hashemi, S. M. Mousavi, and S. Ramakrishna, "Effective removal of mercury, arsenic and lead from aqueous media using polyaniline- $\mathrm{Fe}_{3} \mathrm{O}_{4}$ - silver diethyldithiocarbamate nanostructures," Journal of Cleaner Production, vol. 239, p. 118023, 2019.

[42] H. Saghatchi and R. Ansari, "Application of magnetic polyaniline nanocomposite for separation of uranyl ions from aqueous solutions," Separation Science and Technology, vol. 53, no. 15, pp. 2486-2499, 2018.

[43] D. D. Shao, G. S. Hou, J. X. Li, T. Wen, X. Ren, and X. Wang, "PANI/GO as a super adsorbent for the selective adsorption of uranium(VI)," Chemical Engineering Journal, vol. 255, pp. 604-612, 2014.

[44] B. Li, L. J. Ma, Y. Tian et al., "A catechol-like phenolic ligandfunctionalized hydrothermal carbon: one-pot synthesis, characterization and sorption behavior toward uranium," Journal of Hazardous Materials, vol. 271, pp. 41-49, 2014.

[45] M. Gholinejad, J. Ahmadi, and C. Najera, "Silica microparticles supported gold and copper ferrite nanoparticles: a magnetically recyclable bimetallic catalyst for Sonogashira reaction," ChemistrySelect, vol. 1, no. 3, pp. 384-390, 2016.

[46] J. Kurian and M. J. Mathew, "Structural, optical and magnetic studies of $\mathrm{CuFe}_{2} \mathrm{O}_{4}, \mathrm{MgFe}_{2} \mathrm{O}_{4}$ and $\mathrm{ZnFe}_{2} \mathrm{O}_{4}$ nanoparticles prepared by hydrothermal/solvothermal method," Journal of Magnetism and Magnetic Materials, vol. 451, pp. 121-130, 2018.

[47] A. H. Jawad and A. S. Abdulhameed, "Facile synthesis of crosslinked chitosan-tripolyphosphate/kaolin clay composite for decolourization and COD reduction of remazol brilliant blue R dye: optimization by using response surface methodology," Colloids and Surfaces A: Physicochemical and Engineering Aspects, vol. 605, article 125329, 2020.

[48] Z. D. Zujovic, Y. Wang, G. A. Bowmaker, and R. B. Kaner, "Structure of ultralong polyaniline nanofibers using initiators," Macromolecules, vol. 44, no. 8, pp. 2735-2742, 2011.

[49] N. N. A. Malek, A. H. Jawad, A. S. Abdulhameed, K. Ismail, and B. H. Hameed, "New magnetic Schiff's base-chitosan- 
glyoxal/fly ash $/ \mathrm{Fe}_{3} \mathrm{O}_{4}$ biocomposite for the removal of anionic azo dye: an optimized process," International Journal of Biological Macromolecules., vol. 146, pp. 530-539, 2020.

[50] A. H. Jawad, N. S. A. Mubarak, and A. S. Abdulhameed, "Tunable Schiff's base-cross-linked chitosan composite for the removal of reactive red 120 dye: adsorption and mechanism study," International journal of biological macromolecules, vol. 142, pp. 732-741, 2020.

[51] M. F. Cheira, "Synthesis of aminophosphonate-functionalised $\mathrm{ZnO}$ /polystyrene-butadiene nanocomposite and its characteristics for uranium adsorption from phosphoric acid," International Journal of Environmental Analytical Chemistry, pp. 1$25,2019$.

[52] Z. Dousti, L. Dolatyari, M. R. Yaftian, and S. Rostamnia, "Adsorption of Eu(III), Th(IV), and U(VI) by mesoporous solid materials bearing sulfonic acid and sulfamic acid functionalities," Separation Science and Technology, vol. 54, no. 16, pp. 2609-2624, 2019.

[53] Y. Kou, L. Zhang, B. Liu, L. Zhu, and T. Duan, "Phosphonate modified $\mathrm{MoS}_{2}$ composite material for effective adsorption of uranium(VI) in aqueous solution," Journal of Radioanalytical and Nuclear Chemistry, vol. 323, no. 1, pp. 641-649, 2020.

[54] H. Yang, H. Ding, X. Zhang, X. Luo, and Y. Zhang, "Immobilization of dopamine on Aspergillus niger microspheres (AM/PDA) and its effect on the U(VI) adsorption capacity in aqueous solutions," Colloids and Surfaces a-Physicochemical and Engineering Aspects, vol. 583, article 123914, 2019.

[55] F. Ashrafi, M. Firouzzare, S. J. Ahmadi, M. Sohrabi, and M. Khosravi, "Preparation and modification of forcespun polypropylene nanofibers for adsorption of uranium (VI) from simulated seawater," Ecotoxicology and environmental safety, vol. 186, p. 109746, 2019. 